\title{
The Effect of Marital Status and Children on Savings and Portfolio Choice
}

\author{
David A. Love*
}

September 24, 2008

\begin{abstract}
This paper investigates the impact of demographic shocks on optimal decisions about saving, life insurance, and, most centrally, asset allocation. We analyze these choices within the framework of a life-cycle model that features exogenous changes in family composition, heterogeneity in lifetime income, and uninsurable fluctuations in earnings and medical costs. Our analysis indicates that marital-status transitions and children can have important effects on optimal household decisions. Widowhood induces sharp reductions in the portfolio shares in stock, and the impact is largest for women and individuals with children. Divorce causes men and women to reallocate their portfolios in different directions; men choose much riskier allocations, while women opt for safer ones. Children play a fundamental role in the optimal portfolio decisions. Men with children, for example, increase their shares in response to divorce by less than half as much as men without children. Comparing our simulation results with panel-data evidence on stockholding from the PSID and the HRS, we conclude that changes in marital status and children matter empirically as well, but not always in the ways that the model predicts.
\end{abstract}

JEL classification: G11; G22; D91; E21; I10; J12

Keywords: Portfolio choice; mortality risk; marital status; precautionary saving; bequests; risk and uncertainty.

${ }^{*}$ Dept. of Economics, Williams College, Williamstown, MA 01267, david.love@williams.edu. I am grateful to Chris Carroll, Michael Palumbo, Maria Perozek, Lucie Schmidt, and two anonymous referees. 


\section{Introduction}

This paper examines how marital status and children affect optimal life-cycle saving and asset allocation decisions. When people marry, have children, or separate through divorce or widowhood, they can experience dramatic changes in their financial positions. Wealth increases or divides; spending needs change in relation to housing and children; and new expectations are formed regarding future income, longevity, and bequests. Although these are not, strictly speaking, exogenous events, family transitions constitute an important source of risk, with the potential to affect everything from wealth accumulation (Cubeddu and Ríos-Rull, 2005; Scholz and Seshadri, 2007) to the demand for life insurance (Hong and Ríos-Rull, 2006). ${ }^{1}$ Viewed as a source of background risk, there is reason to expect that these shocks to family composition also play a role in determining the demand for risky assets. $^{2}$

This possibility motivates our current study, in which we examine how "family shocks" affect optimal decisions about consumption, life insurance, and asset allocation over the life cycle. Our framework builds on a growing body of life-cycle models that explore different aspects of household portfolio decisions. ${ }^{3}$ We incorporate undiversifiable labor income risk (Bodie et al., 1992; Heaton and Lucas, 2000; Viceira, 2001), an altruistic bequest motive (De Nardi, 2004; Laitner, 2002), out-of-pocket medical expense risk (French, 2005; Hubbard et al., 1995; Palumbo, 1999), a market for life insurance (Fischer, 1973; Hong and Ríos-Rull, 2006), evolving spending needs (Attanasio et al., 1999), exogenous shocks to marital status (Cubeddu and Ríos-Rull, 2005), and an explicit treatment of children (Scholz and Seshadri, 2007). Together, these elements compose a life-cycle model in which households exposed to family shocks must make optimal decisions about consumption, life insurance, and asset allocation in an environment characterized by risky asset returns, labor earnings, medical costs, and mortality.

While most of the components of our modeling framework have been developed in pre-

\footnotetext{
${ }^{1}$ Cubeddu and Ríos-Rull (2005) and Hong and Ríos-Rull (2006) investigate the effects of exogenous changes in marital status on wealth and life insurance. Scholz and Seshadri (2007) study wealth accumulation in a model with exogenous and endogenous fertility.

${ }^{2}$ Several studies demonstrate the theoretical and empirical tendency for background risk to reduce the share of risky assets. See, for example, Koo (1998), Heaton and Lucas (2000), Kimball and Elmendorf (2000), Viceira (2001), and Haliassos and Michaelides (2003).

${ }^{3}$ Research on optimal portfolio choice over the life cycle continues to expand. It includes work on the tendency of housing to crowd out the risky allocation of the young (Cocco, 2005; Yao and Zhang, 2005; $\mathrm{Hu}, 2005$ ), the ability of fixed costs to explain low observed rates of participation (Vissing-Jorgensen, 2002; Gomes and Michaelides, 2005), the effect of luxury goods and nonhomothetic utility on the relationship between wealth and allocation (Wachter and Yogo, 2007), the role of medical expenses as background risk (Luo, 2006; Love and Perozek, 2007; Pang and Washawsky, 2007), and the interaction between portfolio choice and the demand for annuities (Horneff et al., 2007). The foundation of our model, however, derives from the life-cycle asset allocation studies of Cocco et al. (2005), Gomes and Michaelides (2005), and Cocco (2005), and from the normalized buffer-stock consumption model of Carroll (1997).
} 
vious studies, ours is the first life-cycle paper, to our knowledge, to include an explicit treatment of shocks to both marital status and children. ${ }^{4}$ It is also the first life-cycle paper on portfolio choice to focus on either marital status or children as a source of background risk. ${ }^{5}$ That family shocks have received relatively scant attention in the life-cycle portfolio choice literature is, perhaps, surprising. After all, marital status and children almost certainly affect household resources, preferences, and background risk, and these elements lie at the heart of any analysis of optimal asset allocation and wealth accumulation over the life cycle.

As an illustration of how children and marital status might affect individual portfolio decisions, imagine that a couple with two children living at home gets a divorce. Depending on the legal assignment of custody, the mandated level of child support, anticipated earnings, and the division of household wealth, the ratio of wealth to the present value of future income for each spouse will almost surely differ from the level previously observed in marriage. As Bodie et al. (1992) demonstrate, this ratio is key to understanding optimal asset allocation because it summarizes, at least in part, the exposure of future consumption possibilities to fluctuations in financial markets. The wealth-to-income ratio, however, is not the only channel connecting divorce and portfolio choice. Background risk may also be affected in this example since the former spouses move from living on a combined income to each relying on a potentially more volatile single stream. As several studies have shown, this sort of uninsurable background risk, arising, for example, from labor income, business income, and housing, can have a quantitatively large impact on optimal portfolio decisions. ${ }^{6}$ A final way that the divorce might influence optimal portfolio choice is through its effect on savings as the former spouses update their desired consumption of housing, food, transportation, and child care. Taken together, these changes in wealth, income, and desired consumption may lead to large adjustments in the optimal portfolio of financial assets.

Intuition for the importance of family shocks also comes from recognizing that mari-

\footnotetext{
${ }^{4}$ Section 2 describes how our assumptions about marital status transitions differ from the processes in Cubeddu and Ríos-Rull (2005) and Hong and Ríos-Rull (2006) and how our fertility process differs from the processes considered in Scholz and Seshadri (2007).

${ }^{5}$ The importance of family effects for understanding savings patterns has, however, received attention in the empirical life-cycle consumption literature. The pioneering studies are by Attanasio and Browning (1995), who demonstrate the importance of family effects for explaining the excess sensitivity of consumption to income, and Browning and Ejrnæs (2002), who argue that the precautionary saving motive may be unnecessary to explain the rise in saving early in the life cycle once one controls for children. Scholz and Seshadri (2007), however, show that simply controlling for variation in family size is not enough to reconcile the life-cycle model's predictions with observed consumption patterns. It is the interaction of family size with precautionary effects that is necessary to explain the empirical distribution of wealth.

${ }^{6}$ See Koo (1998) and Heaton and Lucas (2000) for examples of calibrated models of optimal portfolio choice that incorporate background risk in an infinitely-lived representative agent setting. Studies solving finite-period models include Viceira (2001), Bertaut and Haliassos (1997), Haliassos and Michaelides (2003), and Gomes and Michaelides (2005). For more citations and a summary of the empirical evidence on background risk, see Curcuru et al. (2004).
} 
tal status and children may have important interactions, in addition to their independent effects on household decisions. Returning to our previous example, contrast the economic implications of divorce for the two-child couple with those of a childless couple. Members of the childless couple will still experience a change in wealth and income in the event of a divorce, but there will be no additional shock to resources due to child support, college expenses, or differences in scale economies related to the assignment of custody. Given this differential impact on resources, it is reasonable to expect that the childless couple will respond differently to divorce in terms of saving and portfolio choice. In addition, children may also alter households' responses to widowhood. For example, depending on the strength of the bequest motive, surviving spouses with children will tend to have larger amounts of wealth relative to income compared to those without children, leaving them more exposed to market risk.

Previous studies support the intuition that children and marital status can have large effects on life-cycle saving decisions. Scholz and Seshadri (2007) simulate wealth distributions generated by a model that includes both exogenous and endogenous fertility and conclude that children have a substantially larger effect on net wealth compared with the effects of means-tested social insurance programs, which were themselves shown to have a large impact on the wealth accumulation of lower-income households (Hubbard et al., 1995). In terms of marital status, Cubeddu and Ríos-Rull (2005) and (Hong and Ríos-Rull, 2006) conclude that the risks associated with changes in marital status can have a substantial effect on the evolution of wealth and the demand for life insurance.

The contribution of our paper is to demonstrate that, in addition to their effects on wealth and life insurance, family shocks can also have a large impact on optimal portfolio decisions. The importance of family shocks can be seen, at the broadest level, by comparing the average wealth and portfolio shares across marital status categories and the presence of children. We find that households with children tend to accumulate substantially less wealth during the working years but that their slower rates of drawdown in retirement leave them with more savings toward the tail end of life. This trajectory of wealth accumulation is mirrored, in part, by the evolution of portfolio shares. Earlier in the life cycle, households with children hold riskier portfolio shares (by about 10 percentage points) than households without children, but the relationship reverses in retirement. Following the logic in Bodie et al. (1992), a riskier allocation for these younger households is optimal because their consumption streams are less dependent on the performance of financial markets. In retirement, however, children provide an incentive to maintain wealth for bequests, and the resulting increase in the wealth-to-income ratio makes households increasingly sensitive to stock market volatility. Looking at the average shares alone, however, does not tell us how changes in marital status affect portfolio decisions at the time of the shock. 
To examine the direct response of portfolio allocations to changes in family composition, therefore, we conduct two separate experiments. In the first, we compute the average change in the portfolio shares at the time of a marital status transition, with an adjustment for the "typical" change experienced by households who did not undergo a change in marital status. This experiment is designed to uncover the effects of family shocks on households whose particular wealth and income levels are the outcomes of simulated life-cycle histories. In the second, we examine changes in the decision rules themselves, which allows us to trace out the response of the portfolio shares over a range of wealth-to-income ratios.

Both experiments demonstrate the importance of the interaction between marital status and children, particularly in the cases of divorce and widowhood. In the simulation experiment, for example, working-age men without children respond to divorce by tilting their portfolios toward stocks by 10 to 20 percentage points. Those without children, in contrast, increase their shares by one-half to two-thirds as much. Divorce affects the shares of men and women in opposite directions. While women respond to divorce by choosing a safer allocation, men move toward a riskier one, resulting in a net difference in allocations by gender of about 20 percentage points. Widowhood leads to sharp downward adjustments for both men and women, but the effects are largest for women and individuals with children. The decision rules experiment provides some insight into how changes in the optimal share vary with wealth. The decision rules indicate that marital status and children have the largest influence at lower levels of wealth (but not so low that stocks strictly dominate the safe asset) and that the impact of children on portfolio decisions is largest for divorced working-age men and smallest for retired widows.

The predictions generated by the model suggest that children and marital status may indeed be important determinants of savings and portfolio choice. We test this prediction using panel data from the Health and Retirement Study (HRS) and the Panel Study on Income Dynamics (PSID). The marginal effects estimates from panel tobit regressions on the portfolio share in stocks provide preliminary evidence that marital status and children influence portfolio decisions. For example, many of the estimates on the marital status indicator variables are in the 5-10 percentage point range, and a number are statistically significant. The signs, however, do not always agree with the patterns in the model simulations. For example, while the PSID regressions estimate a 6.3 percentage point decline in the stock share for divorced, high school-educated women, which is consistent with the model's predictions, no such empirical relationship emerges for college graduates.

The remainder of our paper proceeds as follows. Section 2 presents a model of demographics and household portfolio choice and characterize the solution. Section 3 discusses the parameterization of the model and our procedure for matching the median wealth levels in the data. Section 4 presents our main findings from the model simulations, and Section 
5 compares those results with panel-data evidence in the HRS and the PSID. The final section concludes.

\section{The Model}

Our economy extends the life-cycle asset allocation models in Cocco et al. (2005) and Gomes and Michaelides (2005) by introducing marital status transitions (as in Cubeddu and RíosRull, 2005), life insurance (as in Hong and Ríos-Rull, 2006), and children (as in Scholz and Seshadri, 2007). ${ }^{7}$ Individuals differ by age $t \in\{20, \ldots, 100\}$, education $e \in\{$ high school, college $^{8}$, sex $g \in\{$ male, female $\}$, marital status $m \in$ \{never-married, married, divorced, widowed\}, and the number and ages of children.

Children are born according to fertility probabilities that depend on age, education, and marital status, and they remain in the household until age 18. From ages 18 to 22, children attend post-secondary school that is financed by the parents. As we explain in the following section, the ages of the children can be fully summarized by two discrete state variables: the number of children born before the mother is $30, n_{e}$, and the number of children born when the mother is 30 or older, $n_{l}$ ( $e$ and $l$ stand for "early" and "late"). Together, $n_{e}$ and $n_{l}$ sum to the total number of children born to an individual, denoted $n$.

Throughout their life cycles, individuals face exogenous changes in marital status (e.g., from married to divorced), with probabilities that depend on age, education, and gender. ${ }^{9}$ We describe the process governing marital transitions in greater detail in Section 3.3. For notational compactness, it will be helpful to let $\iota=\left\{m, g, e, n_{e}, n_{l}\right\}$ index a household by

\footnotetext{
${ }^{7}$ Cubeddu and Ríos-Rull (2005) and Hong and Ríos-Rull (2006) model the effects of marital status changes on wealth and life insurance in a general equilibrium setting. While children enter the preferences of households in their model, they arrive deterministically in accordance with the population growth rate of the economy. Scholz and Seshadri (2007), in contrast, simulate household wealth in a model that abstracts from changes in marital status but that introduces children both exogenously and endogenously. Our treatment of children differs from Scholz and Seshadri's in two respects. First, whereas their exogenous specification of fertility deterministically fixes the number and ages of children, ours assumes that children are born probabilistically, in accordance with data on natality. This uncertainty allows birth itself to represent a source of family shocks. Second, the specification of children in our model introduces some uncertainty about the spacing of children by distinguishing between early and late births.

${ }^{8}$ Although we also estimated and solved the model for individuals with less than a high school degree, we focus on high school and college graduates because the results for the lowest two categories are qualitatively similar and because the observed rates of stockholding for high school dropouts are quite low.

${ }^{9}$ The assumption that marital status and children evolve exogenously rules out some interesting, and potentially important, interactions between risk preferences and decisions about marriage and fertility (Schmidt, 2008). We do not model endogenous fertility, as is done in Scholz and Seshadri (2007), because of a technical restriction on the intertemporal elasticity of substitution (IES). The most common way of modeling endogenous fertility is to adopt the quantity/quality framework of Becker and Barro (1988). This framework requires, however, that the flow utility must be positive in order for households to optimally choose a non-zero number of children. With CRRA preferences, flow utility will be non-zero if and only if the coefficient of relative risk aversion is less than 1 , a restriction that generally leads to corner solutions of $100 \%$ stock holding in models of portfolio choice.
} 
marital status, gender, education, and number of children.

At the beginning of each period $t$, households form expectations about resources and demographic transitions and select a combination of consumption $C_{t}$, life insurance $Z_{t}$, and a portfolio share of the risky asset $\varsigma_{t}$ to achieve the standard goal of maximizing expected lifetime utility. ${ }^{10}$ The preference structure for married couples differs from that of singles, and we describe them in turn.

\subsection{Preferences for a single household}

Single households ( $m \neq$ married) enter each period with cash on hand $X_{t}$, out of which they consume, purchase life insurance, and save for future consumption and bequests. Expenditures must be financed out of a combination of savings from the previous period, $R_{t+1}\left(X_{t}-C_{t}-Z_{t}\right)$, and income net of medical expenses, taxes, and housing costs, $\left(1-h_{t+1, \iota^{\prime}}\right) Y_{t+1, \iota^{\prime}}$, where $\iota^{\prime}$ denotes the household's index in the next period, $R_{t+1}$ is the stochastic portfolio rate of return, $h_{t+1, \iota}$ is the fraction of income spent on housing, and $Y_{t+1, \iota^{\prime}} \geq 0$ is non-asset "post-government" income (net of taxes and public transfers).

In addition to the possibility of changing marital status, individuals alive at age $t$ face a probability $1-p_{t, \iota}$ of dying before the next period that depends on age, sex, marital status, and education. In the event of death, an insurance benefit $Q_{t+1}$ increases the amount of cash on hand available for bequests, where $Q_{t+1}=\Psi_{t} Z_{t}$ is a linear function of the premium $Z_{t}$. If the individual survives, $Q_{t+1}=0$. The value function for singles can be written as ${ }^{11}$

$$
V_{t, \iota}\left(X_{t}\right)=\max _{C_{t}, Z_{t}, \varsigma_{t}}\left\{u_{t, \iota}\left(C_{t}\right)+\beta p_{t, \iota} \mathbf{E}_{t} V_{t+1, \iota^{\prime}}\left(X_{t+1}\right)+\beta\left(1-p_{t, \iota}\right) \mathbf{E}_{t} B_{t, \iota}\left(X_{t+1}\right)\right\},
$$

where

$$
\begin{aligned}
X_{t+1} & =R_{t+1}\left(X_{t}-C_{t}-Z_{t}\right)+\left(1-h_{t+1, \iota^{\prime}}\right) Y_{t+1, \iota^{\prime}}+\Lambda_{t+1, \iota^{\prime}} P_{t+1, \iota^{\prime}}+Q_{t+1} \\
R_{t+1} & =R+\left(R_{t+1}^{e}-R\right) \varsigma_{t} \\
X_{t} & \geq C_{t}+Z_{t} \\
0 \leq & \varsigma_{t} \leq 1 .
\end{aligned}
$$

\footnotetext{
${ }^{10}$ We rule out the possibility of endogenous annuitization because annuity markets are thin and because adding an annuity decision would complicate the household's choice problem. Studies that explicitly model imperfect annuity markets find that households tend to purchase more annuities as they age (Horneff et al., 2007) and that the demand for annuities depends on the extent of background risk arising, for example, from health expenses (Pang and Washawsky, 2007). A well-developed market for annuities would provide households with an important lever for hedging against mortality risk. Empirically, however, the demand for private annuities is quite thin - potentially optimally so (Benitez-Silva, 2003).

${ }^{11}$ Technically, the value function also takes permanent income as an argument. We omit the argument for compactness and because we will eventually normalize the problem by permanent income.
} 
In the equations above, $u_{t, \iota}($.$) is the period utility function, \beta$ is the discount factor, $\mathbf{E}_{t}$ is the expectations operator, $P_{t+1, \iota^{\prime}}$ is the level of permanent income, and $B_{t, \iota}($.$) is a bequest$ function. Expectations are taken over the distribution of returns, permanent and transitory income, births, and marital status transitions. $\Lambda_{t+1, l^{\prime}}$ denotes the change in assets (as a fraction of permanent income $P_{t+1, \iota^{\prime}}$ ) that occurs when a household experiences a change in marital status. If there is no change in marriage, divorce, or widowhood, $\Lambda_{t+1, \iota^{\prime}}=0$. Finally, the portfolio return $R_{t+1}$ is a weighted average of the gross risk-free rate $R$ and the gross risky return on equities $R_{t+1}^{e}$.

Current utility depends on age, gender, and marital status because of household economies of scale, which are themselves a function of the number of adults and children living in the household. Each member of the household derives iso-elastic utility from consumption adjusted for scale economies. ${ }^{12}$

$$
u_{t, \iota}\left(C_{t}\right)=\frac{1}{1-\rho}\left(\frac{C_{t}}{\eta_{t, \iota}}\right)^{1-\rho}
$$

where $\rho$ is the coefficient of relative risk aversion, $1 / \rho$ is the elasticity of intertemporal substitution, and $\eta_{t, \iota}$ is the household equivalence scale. Only households who have children receive utility bequests, which are valued according to the function ${ }^{13}$

$$
B_{t, \iota}\left(X_{t}\right)=\left\{\begin{array}{cc}
\frac{b \sqrt{n}}{1-\rho}\left(\frac{X_{t}}{b \sqrt{n}}\right)^{1-\rho} & \text { if } n>0 \\
0 & \text { if } n=0
\end{array}\right.
$$

where $b$ determines the curvature of the marginal value of bequests. The bequest function is similar to the one used in Gomes and Michaelides (2005), except that in our specification, the value of bequests depends on the number of children. The marginal value of bequests

\footnotetext{
${ }^{12}$ Some previous papers specify an Epstein-Zin utility function in order to separate risk aversion from the elasticity of intertemporal substitution (EIS), which in the CRRA specification are inverses of each other. The main advantage of separating risk aversion and the willingness to substitute intertemporally has to do with the participation margin of stock holding. As discussed in Gomes and Michaelides (2005), households with low risk aversion and low intertemporal elasticity are the ones most likely to stay away from the stock market when there are modest participation costs. A high intertemporal elasticity of substitution increases the desire to save, which in turn increases the demand to participate in the stock market. Thus, the Epstein-Zin specification helps the model capture an important aspect of stockmarket participation in the U.S. - namely, low income households tend to save little and hold zero stocks. Conditional on participation, however, a model with Epstein-Zin utility still generates the counterfactual prediction that households with the lowest wealth-to-income ratios will place the highest fraction of their wealth in stocks. We do not model Epstein-Zin preferences because the primary goal of the paper is to explain patterns of stock allocation rather than participation, and because the recursive nature of those preferences increases the time necessary to compute optimal consumption.

${ }^{13}$ The bequest motive does not take into account the optimal wealth and portfolio decisions of the children, which could well be important for the allocation decisions of parents intending to leave an inheritance. The parents' and children's decisions would ideally be jointly determined in the model, but this kind of nested solution raises complications that are beyond the scope of this current paper.
} 
for a households with children is $B_{t, \iota}^{\prime}\left(X_{t}\right)=\left[(b \sqrt{n}) / X_{t}\right]^{\rho}$, which for $\rho>1$ is increasing in $b$ and $n$ and decreasing in $X_{t}$.

\subsection{Preferences for a married couple}

The married household's problem is complicated by the fact that spouses must choose consumption, insurance, and a portfolio allocation while having potentially competing interests in terms of future preferences. Following Cubeddu and Ríos-Rull (2005) and Hong and Ríos-Rull (2006), we assume that married couples solve a joint maximization problem with weights $\xi_{m}$ and $\xi_{f}=1-\xi_{m}$ on the husband's and the wife's preferences. We assume further that a married couple is constrained to enjoy the same consumption in period $t$, but that future choices can differ in the event of a separation due to death or divorce. Because of competing interests within the household, a spouse's current marginal utility will typically not equal the expected marginal value from his or her future consumption stream.

We depart from Cubeddu and Ríos-Rull (2005) and Hong and Ríos-Rull (2006) by assuming that spouses place an altruistic weight $\lambda$ on each other's value function in the event of death. Motivation for this assumption comes from the following thought experiment. Imagine that a married couple learns with perfect certainty that the husband will be dead the following year. In the absence of altruism, the husband would pressure the wife to go on a household consumption binge with him in the current period, eating into resources that would otherwise be available to the wife later as a widow. (The husband receives no utility in the next period, while the wife's expected marginal value is reduced by the decision weight $\xi_{f}$.) As a result, the wife would be forced to reduce consumption following her husband's death, leading to a sudden increase in her marginal value function. If, on the other hand, spouses value each other's utility in widowhood, they would be less apt to negotiate for higher current consumption because of mortality discounting. Since altruism for the other spouse is unlikely to obtain in the event of divorce, we assume that spouses place no weight on the other's utility in the post-divorce state of the world.

Letting $\iota^{*}$ denote the opposite gender's index, we can write the married household's problem $(m=$ married) as follows

$$
\begin{array}{r}
V_{t, \iota}\left(X_{t}\right)=\max _{C_{t}, Z_{t}, \varsigma_{t}}\left\{u_{t, \iota}\left(C_{t}\right)+\beta\left(1-p_{t, \iota}\right)\left(1-p_{t, \iota^{*}}\right) \mathbf{E}_{t} B_{t, \iota}\left(X_{t+1}\right)\right. \\
+\xi_{m} \beta\left[p_{t, \iota} \mathbf{E}_{t} V_{t+1, \iota^{\prime}}\left(X_{t+1}\right)+\lambda p_{t, \iota^{*}}\left(1-p_{t, \iota}\right) \mathbf{E}_{t} V_{t+1, \iota^{*^{\prime}}}\left(X_{t+1}\right)\right] \\
\left.+\left(1-\xi_{m}\right) \beta\left[p_{t, \iota^{*}} \mathbf{E}_{t} V_{t+1, \iota^{*}}\left(X_{t+1}\right)+\lambda p_{t, \iota}\left(1-p_{t, \iota^{*}}\right) \mathbf{E}_{t} V_{t+1, \iota^{\prime}}\left(X_{t+1}\right)\right]\right\},
\end{array}
$$

subject to equations (2)-(5). The expectations in the value function are taken over marital status, children, mortality (and therefore insurance payouts), asset returns, and income 
shocks. The first term, $u_{t, \iota}\left(C_{t}\right)$, is the utility that each spouse receives from the household consuming $C_{t}$ in the current period. The next term captures the value each spouse receives from leaving his or her children the remaining wealth $X_{t+1}$, which includes the death benefit $Q_{t+1}$. (We make the simplifying assumption that a married couple purchases life insurance only for the husband.) The third term represents the weighted value function of the husband, which takes into account the wife's utility in the event he leaves her a widow. The final term represents the symmetric value function for the wife.

\subsection{Income}

Following Carroll (1997), we decompose household income into permanent and transitory components. The permanent component $P_{t+1, \iota^{\prime}}$ depends on the previous realization of permanent income $P_{t, \iota}$, a demographic trend $G_{t+1, \iota^{\prime}}$ that depends on both current and future demographic states (the notation suppresses the dependence on $\iota$ ), and a log-normally distributed shock $N_{t+1, \iota^{\prime}}$. Income in period $t+1$ equals the permanent realization times the transitory shock $\Theta_{t+1, \iota^{\prime}}$.

$$
\begin{aligned}
& Y_{t+1, \iota^{\prime}}=P_{t+1, \iota^{\prime}} \Theta_{t+1, \iota^{\prime}} \\
& P_{t+1, \iota^{\prime}}=G_{t+1, \iota^{\prime}} P_{t, \iota} N_{t+1, \iota^{\prime}},
\end{aligned}
$$

where $\log \left(N_{t, \iota}\right) \sim \mathcal{N}\left(-\sigma_{n, \iota}^{2} / 2, \sigma_{n, \iota}^{2}\right)$ and $\log \left(\Theta_{t}\right) \sim \mathcal{N}\left(-\sigma_{\theta, \iota}^{2} / 2, \sigma_{\theta, \iota}^{2}\right)$.

There are two things to note about this formulation of income. First, the trend component of permanent income depends on age, education, gender, marital status, household size, child support, and college expenses, and is therefore subject to shocks as households move from one demographic state to another. A movement from married to divorced, for example, would lead to a sharp decrease in the value of $G_{t+1, \iota, \iota^{\prime}}$, both because of the direct impact of divorce on earnings and because of the indirect effect of child support payments. Second, although the notation suppresses the distinction, the shocks to permanent and transitory income differ across the working and retirement portions of life. For workers, variation in income comes predominantly from changes in productivity and unemployment, while for retirees, much of the variation comes from out-of-pocket medical expenditures. Our formulation of income net of taxes and medical costs implicitly assumes that out-ofpocket medical expenses are proportional to permanent income.

Apart from the inclusion of life insurance and demographic transitions, the formulation of the single household's value function is standard. The married couple's problem, however, involves a few more complications. 


\subsection{Solving the model}

The solution to the model consists of a set of decision rules for life insurance, portfolio allocation, and consumption. ${ }^{14}$ For each age $t$, household type $\iota$, level of cash on hand $X_{t}$, and permanent income $P_{t, \iota}$, we approximate these decision rules by numerically solving a representative household's first order conditions. Because the structure of the first order conditions for married couples parallels that for singles (with additional terms to keep track of the other spouse's utility), we describe the single household's problem and leave the married couple's as a straightforward extension.

The assumptions of iso-elastic utility and bequests, in addition to the unit root in income, allow us to normalize the problem by permanent income and solve the last period's problem for each household index $\iota$. Letting lowercase variables denote the normalized versions of uppercase variable (e.g., $x_{t}=X_{t} / P_{t}$ ), the normalized value functions for singles can be written as

$$
\begin{aligned}
\mathbf{v}_{t, \iota}\left(x_{t}\right)=\max _{x_{t}, z_{t}, \varsigma_{t}} & \left\{u_{t, \iota}\left(c_{t}\right)+\beta p_{t, \iota} \mathbf{E}_{t} \Gamma_{t+1, \iota^{\prime}}^{1-\rho} \mathbf{v}_{t+1, \iota^{\prime}}\left(R_{t+1} a_{t} / \Gamma_{t, \iota^{\prime}}+\left(1-h_{t+1, \iota^{\prime}}\right) \Theta_{t+1}+\Lambda_{t+1, \iota^{\prime}}\right)\right. \\
& \left.+\beta\left(1-p_{t, \iota}\right) \mathbf{E}_{t} \Gamma_{t+1, \iota^{\prime}}^{1-\rho} B_{t, \iota}\left(\left[R_{t+1} a_{t}+q_{t+1}\right] / \Gamma_{t, \iota^{\prime}}\right)\right\}
\end{aligned}
$$

where $\mathbf{v}_{t, \iota}\left(x_{t}\right)=V_{t, \iota}\left(X_{t}\right) / P_{t}^{1-\rho}$ is the normalized value function, $a_{t}=x_{t}-c_{t}-z_{t}$ is the amount of savings at the end of period $t, \Gamma_{t+1, \iota^{\prime}}=G_{t+1, \iota^{\prime}} N_{t+1, \iota^{\prime}}$ is the stochastic growth in permanent income, and $q_{t+1}=\Psi_{t} z_{t}$ is the life insurance payout in the event of death.

\subsubsection{First order conditions}

With an approximate version of (11) in hand, we can calculate period t's optimal decisions by solving for the values of $z_{t}, \varsigma_{t}$, and $c_{t}$ that satisfy the following first order conditions.

Life insurance: The envelope condition requires that $u_{t, \iota}^{\prime}\left(c_{t}\right)=\mathbf{v}_{t, \iota}^{x}\left(x_{t}\right)$, and we can write the first order condition with respect to life insurance $z_{t}$ as ${ }^{15}$

$$
\begin{aligned}
& \beta p_{t, \iota} \mathbf{E}_{t} R_{t+1} u_{t+1, \iota^{\prime}}^{\prime}\left(\Gamma_{t+1, \iota^{\prime}} \mathbf{c}_{t+1, \iota^{\prime}}\right)+ \\
& \beta\left(1-p_{t, \iota}\right) \mathbf{E}_{t}\left(R_{t+1}-\Psi_{t}\right) B_{t, \iota}^{\prime}\left(R_{t+1} a_{t}+q_{t+1}\right)=0,
\end{aligned}
$$

where $\mathbf{c}_{t+1, \iota^{\prime}}$ is next period's decision rule for consumption:

$$
\mathbf{c}_{t+1, \iota^{\prime}}\left(x_{t+1}\right)=\mathbf{c}_{t+1, \iota^{\prime}}\left(R_{t+1} a_{t} / \Gamma_{t, \iota^{\prime}}+\left(1-h_{t+1, \iota^{\prime}}\right) \Theta_{t+1}+\Lambda_{t+1, \iota^{\prime}}\right) .
$$

\footnotetext{
${ }^{14}$ For a detailed introduction to solving models of this type, see Carroll (2006) and Carroll (2007).

${ }^{15}$ In deriving the first-order conditions, we take advantage of the property that the marginal utility and bequest functions are homogeneous of degree $-\rho$. Homogeneity implies that $\Gamma_{t+1, \iota^{\prime}}^{-\rho} u_{t+1, \iota^{\prime}}^{\prime}\left(\mathbf{c}_{t+1, \iota^{\prime}}\right)=$ $u_{t+1, \iota^{\prime}}^{\prime}\left(\Gamma_{t+1, \iota^{\prime}} \mathbf{c}_{t+1, \iota^{\prime}}\right)$ and $\Gamma_{t+1, \iota^{\prime}}^{-\rho} B_{t, \iota}^{\prime}\left(\left[R_{t+1} a_{t}+q_{t+1}\right] / \Gamma_{t+1, \iota^{\prime}}\right)=B_{t, \iota}^{\prime}\left(R_{t+1} a_{t}+q_{t+1}\right)$.
} 
In equation (12), the first term represents the utility loss due to the cost of purchasing life insurance. Each dollar of life insurance reduces next period's cash on hand by $R_{t+1}$, causing a reduction in expected utility of $\beta p_{t, \iota} \mathbf{E}_{t} R_{t+1} u_{t+1, \iota^{\prime}}^{\prime}\left(\Gamma_{t+1, \iota^{\prime}} \mathbf{c}_{t+1, \iota^{\prime}}\right)$. The second term captures the net expected marginal benefit associated with an additional dollar of life insurance: Insurance reduces expected bequethable assets by $R_{t+1}$, but there is also an expected payout equal to $\Psi_{t}$ dollars. The optimal level of insurance sets the expected net marginal gains to zero.

Portfolio allocation: Similarly, we can write the first order condition for the portfolio share as

$$
\begin{aligned}
& \beta p_{t, \iota} \mathbf{E}_{t}\left(R_{t+1}^{e}-R\right) a_{t} u_{t+1, \iota^{\prime}}^{\prime}\left(\Gamma_{t+1, \iota^{\prime}} \mathbf{c}_{t+1, \iota^{\prime}}\right)+ \\
& \beta\left(1-p_{t, \iota}\right) \mathbf{E}_{t}\left(R_{t+1}^{e}-R\right) a_{t} B_{t, \iota}^{\prime}\left(R_{t+1} a_{t}+q_{t+1}\right)=0 .
\end{aligned}
$$

Except for the terms related to marital status (e.g., the transition parameter $\Lambda_{t+1, \iota^{\prime}}$ inside $\mathbf{c}_{t+1, \iota^{\prime}}$ ) and life insurance (e.g., $q_{t+1}$ ), this is the standard first-order condition for portfolio choice. The optimal share of risky assets balances the higher expected returns of a portfolio weighted toward stocks with the utility costs of increased volatility.

Consumption: Finally, the first order condition for consumption is

$$
\begin{aligned}
u_{t, \iota}^{\prime}\left(c_{t}\right)=\beta p_{t, \iota} \mathbf{E}_{t} R_{t+1} u_{t+1, \iota^{\prime}}^{\prime} & \left(\Gamma_{t+1, \iota^{\prime}} \mathbf{c}_{t+1, \iota^{\prime}}\right)+ \\
& \beta\left(1-p_{t, \iota}\right) \mathbf{E}_{t} R_{t+1} B_{t, \iota}^{\prime}\left(R_{t+1} a_{t}+q_{t+1}\right) .
\end{aligned}
$$

Given end-of-period savings $a_{t}$, and decision rules for life insurance and the stock share, we can immediately determine the value of consumption by first taking the expectations of the marginal value function and then applying the inverse marginal utility function to the result. As Carroll (2006) explains, this can lead to impressive gains in computational efficiency as long as we are willing to work with end-of-period savings $a_{t}$ rather than beginning of period cash on hand $x_{t}$.

\section{Estimation and Calibration}

Most of the parameters and transition processes in the model depend either directly or indirectly on the composition of the household - on marital status and on the number and ages of children. This section details the nature of this dependency and describes how it affects our estimation of the model's key parameters. The first part of the section discusses the parameters most directly linked to household finance and net wealth - the age profiles and covariance structures of income, the evolution of housing costs, the change in wealth due 
to a marital transition, the asset return process, and the structure of life insurance. The next part discusses the specification of children in the model - when they are born, how they are spaced, and what they imply for child support payments and college expenses. The section then turns to the transition process governing movements between marriage, divorce, and widowhood. It concludes by describing household preferences and the estimation procedure for matching the model's simulated wealth levels to those in the data.

\subsection{Income, Housing, and Assets}

\subsubsection{Income during the working life}

Income depends on education, age, gender, marital status, and the number and ages of children. We estimate age profiles of pre-retirement income and their associated covariance structures using unbalanced panel data from the 1980-2003 waves of the Panel Study of Income Dynamics (PSID). Our definition of income is a broad, post-government concept that sums household labor earnings and public transfers and subtracts income taxes and payroll taxes of the household head and the spouse, all converted into 2006 dollars using the CPI-U. ${ }^{16}$ We restrict the sample to respondents aged 20-65 with no additional adults apart from a spouse living in the household and with incomes between $\$ 3,000$ and $\$ 3,000,000 .{ }^{17}$ Finally, to maintain a nationally representative sample of households, we eliminate observations from the SEO oversample of low-income households.

We estimate fixed-effects regressions of the natural logarithm of after-tax income on a full set of age dummies for the respondent, and the numbers of children in different age brackets living in the household. Because we have insufficient data to obtain clean estimates for each marital status subsample (i.e., married, never-married, divorced, and widowed), we instead run separate regressions for single men, single women, and married couples in each education group. ${ }^{18}$ Following Cocco et al. (2005) and others, we obtain our income profiles

\footnotetext{
${ }^{16}$ Our definition of income is similar to that in Cocco et al. (2005) and Gomes and Michaelides (2005). Public transfers include AFDC, unemployment compensation, SSI, food stamps, and other welfare payments. We exclude asset income and private transfers (child support, alimony, and income receipts from other nonhousehold members) from our definition because we model these as separate processes.

${ }^{17}$ We exclude observations with additional adults in order to obtain tighter estimates on the average income profiles and variance processes for the family structure modeled in our paper. Allowing for cohabitation (with no legal protection of assets or income) would introduce an additional source of income variation that cannot be perfectly absorbed through a linear control for family size. While the exclusion of these households makes little difference for the estimated average income profiles (apart from sharply increasing the significance of the estimates on the age dummies), it does generate slightly smaller estimates for the transitory and permanent variances. In terms of our restriction on income, we drop households with very low levels of post-government income (i.e., below $\$ 3,000$ ) because we are concerned about measurement error, and we drop those with very high incomes (i.e., above $\$ 3,000,000)$ to reduce the influence of rich outliers.

${ }^{18}$ Note that even if we were able to obtain clean estimates of the income processes for each of our model's marital status categories, we would then confront an even stronger question about the exogeneity of the differences across marital states. For example, a never-married male in the data might earn less than a
} 
by first fitting a third-degree polynomial to the age dummy coefficients in each specification and then modeling retirement income as a constant fraction of final working-period income. We estimate these fractions, or replacement rates, by first running fixed-effects regressions of log income on age dummies for respondents aged 55 to 90 in the 1992-2006 waves of the HRS. For each marital status, gender, and education group, we define the replacement rate as the average income implied by the age dummy coefficient estimates for ages 55-62 divided by the implied average income for ages $67-80$.

Table 1 reports the fitted polynomial coefficients, replacement rates, and coefficient estimates on the number and ages of children living at home. The sign pattern on the age polynomials generates familiar hump-shaped income profiles, shown by marital status and education in Figure 1. The results in the table indicate that younger children living at home reduce the average incomes of single females and married couples. (The estimates for single males are very imprecisely estimated and essentially irrelevant since our model assumes that, except in the case of widowhood, women are the custodial parents.) We incorporate the effects of children into our income process by first fitting a quadratic through the age dummy coefficients and then normalizing the resulting function so that children have no effect on long-term income. ${ }^{19}$ The normalized process implies that college-educated single females experience a decrease in household income of about $25 \%$ with the birth of a child, which tapers off to a $0 \%$ change 18 years later. The initial change for a single female high school graduate is about $15 \%$, and the change for married couples in each education category is around $7 \%$.

We estimate the variances of permanent and transitory income following the decomposition procedure in Carroll and Samwick (1997). ${ }^{20}$ The estimated transitory and permanent variances for each of our educational groups are reported at the bottom of Table 1 and fall within the range of estimates in Carroll (1992) and Cocco et al. (2005).

\subsubsection{Retirement income net of medical costs}

During the working years, fluctuations in after-tax income derive primarily from spells of unemployment, job changes, and productivity shocks. Retirement income, however, consists of regular payments from Social Security, pensions, and other annuities, which tend to be

typical divorced male of the same age and education, but that doesn't mean that the transition to and from marriage is responsible for the difference.

${ }^{19}$ We assume that additional children lengthen the period of income loss but that they do not lead to further decreases in income (i.e., we do not multiply the age coefficients times the number of children).

${ }^{20}$ The decomposition is as follows. Let $r_{t}^{d}$ denote the $d$-period difference between the unexplained part of after-tax income in period $t+d$ and the unexplained part in period $t$. Then $\operatorname{Var}\left(r_{t}^{d}\right)=d \sigma_{\zeta}^{2}+2 \sigma_{\epsilon}^{2}$, and we can estimate the permanent and transitory variances by regressing $\operatorname{Var}\left(r_{t}^{d}\right)$ on a vector of $d$ 's and a vector of 2's. To reduce bias induced by possible serial correlation in the transitory component, we only include vectors of $r_{t}^{d}$ for $d \geq 2$. 
stable over time. But while income payments in retirement may be relatively constant, out-of-pocket medical expenses can lead to large fluctuations in annual resources (French and Jones, 2004b). We attempt to capture this shift in the source of risk by estimating the variance process of after-tax retirement income net of out-of-pocket medical costs using the 1992-2006 waves of the HRS. We define net retirement income as the sum of Social Security benefits, defined benefit pension payments, annuity flows, government transfers, SSI, veteran's benefits, and other sources of non-asset income less annualized out-of-pocket medical costs. We restrict the sample to respondents aged 60 to 90 with net retirement incomes between $-\$ 20,000$ and $\$ 1,000,000$.

Our estimation of net retirement income follows our procedure for pre-retirement income. For each education category, we estimate a fixed effects regression of log net retirement income on a full set of age dummies and a constant. ${ }^{21}$ Applying the decomposition in Carroll and Samwick (1997), we estimate permanent variances of 0.0125 (s.e. $=0.0026$ ) and 0.0281 (s.e. $=0.0027$ ) and transitory variances of $0.0784($ s.e. $=0.0070)$ and 0.0767 $($ s.e. $=0.0075)$ for high school and college graduates, respectively.

\subsubsection{Income transitions due to marriage or divorce}

The fact that we have separate income profiles for singles and married couples raises the issue of how to deal with transitions in household income due to changes in marital status. If we simply assume that marital transitions trigger a switch from one profile to another, there is a consistency problem in that nothing guarantees that a married couple's income is equal to the combined incomes of the two spouses if they were single. While there are, naturally, reasons to expect that these incomes would differ in practice because of endogenous changes in labor supply and occupational choice, our specification is not rich enough to take these into account.

Instead, our approach assumes that the immediate changes in household income with marriage are due entirely to the combining of the individual income streams. We ensure this by making adjustments (typically very small ones) to the growth rate in permanent income implied by our income profiles. ${ }^{22}$ These adjustments to the growth rate of permanent

\footnotetext{
${ }^{21}$ To allow for negative values of net retirement income, we apply the log transformation: $f(z)=\ln (z+1)$ if $z \geq 0$, and $f(z)=-\ln (-z+1)$ if $z<0$.

${ }^{22}$ Ignoring, for the moment, the effects of age, housing, child support, and college costs on income growth, let $y_{m}, y_{f}$, and $y$ be the estimated levels of permanent income for single males, single females, and married couples. We first compute the ratio of a single male's expected income to a single female's expected income, $g=y_{m} / y_{f}$, which we use to determine the relative contributions of the husband and wife to the married couple's household income. We then solve for the adjusted incomes, $\hat{y}_{m}$ and $\hat{y}_{f}$, such that $\hat{y}_{m}+\hat{y}_{f}=y$. Using the definition of $g$, we find that $\hat{y}_{f}=y /(1+g)$ and $\hat{y}_{m}=g y /(1+g)$, which by construction sum to $y$, the married couple's income. The growth rate in permanent income due to marriage is given by $G=y / \hat{y}_{m}$ for men and $G=y / \hat{y}_{f}$ for women. In the case of divorce, we apply a similar adjustment. For example, divorced men experience a change in household income of $G=\hat{y}_{m} / y$.
} 
income have the advantage that we can retain the differences in the shape of the income profiles across marital status without losing the consistency condition that incomes "add up" in marriage. ${ }^{23}$

\subsubsection{Housing}

The ratio of housing costs to permanent income, $h_{\iota, t}$, depends on family composition and therefore needs to be estimated separately by household type. Gomes and Michaelides (2005) estimate the ratio of annual mortgage and rental costs to income by regressing the housing expenditure ratio on a cubic age polynomial and a set of time dummies. We follow a similar approach and estimate separate fixed-effects regressions for different education, marital status, and gender subsamples in the 1980-2003 waves of the PSID for respondents aged 20 to 75 . Our definition of income-post-government income, excluding private transfers and asset income - is the same as the one used in our estimates of PSID income. We restrict the sample to households with annual housing costs less than income and drop households with annual housing costs in excess of $\$ 1,000,000$. The resulting coefficient estimates, reported in Table 2, imply declining or hump-shaped profiles of housing cost ratios in the range of 15 to 25 percent for most of the working life. Because the profiles imply negative housing costs at more advanced ages, we set the minimum housing cost ratio in the model to zero.

\subsubsection{Wealth changes due to change in marital status}

When couples divorce in the model, we assume that they divide assets equally and pay 10 percent of total assets in divorce costs (meant to capture legal fees and inefficiencies related to the splitting of assets). Although this 50/50 rule is exactly consistent with the community property divorce laws currently in place in nine U.S. states, it probably overstates the equality of division for the majority of states applying some from of equitable distribution, under which assets are divided according to judicial discretion (Stevenson, 2007). ${ }^{24}$

With marriage, households experience an increase in wealth due to the merging of the spouses' assets. Ideally, we would like to estimate the effect of marriage on wealth for each age, education, and marital status group in our model. The PSID and HRS, however, contain insufficient information on marital transitions to obtain such estimates. (For example, only about 1.5-2\% of PSID households report a transition from divorce to marriage, and splitting the sample into age, education, and marital status cells leads to

\footnotetext{
${ }^{23}$ We also solved the model without requiring the incomes to sum up in marriage. In practice, the adjustments make a relatively small difference in our results since the estimated income profiles for married couples are already quite close to the sum of the income profiles for single men and women.

${ }^{24}$ The nine community property states are Arizona, California, Idaho, Louisiana, Nevada, New Mexico, Texas, Washington, and Wisconsin.
} 
very imprecise estimates.) Instead, we take an alternative route and assume that individuals marry a person with the median ratio of wealth to income for the relevant age and education group, with adjustments to make sure that the median combined assets equal the sum of the two individual's assets.

Let $w_{f}$ and $w_{m}$ denote the median wealth levels for single females and single males of a particular age and education group, and let $y$ be the estimated level of a married couple's permanent income. We assume that $\Lambda_{f}=w_{m} / y$ and $\Lambda_{m}=w_{f} / y$, so that the increase in wealth due to marriage is scaled by permanent income. Implicitly, this is tantamount to assuming that marriage is assortative along the dimension of permanent income - men with high permanent incomes marry women with high permanent incomes, and each therefore see a larger absolute increase household wealth upon marriage.

We estimate the increase in household wealth due to marriage for different age, gender, education, and marital status groups using data from the 1999-2005 wealth supplements in the PSID and the 1992-2006 waves of the HRS. We begin by computing the median ratios of wealth to income for single males and single females in each education group for 5 -year age brackets from 20 to 95 . We then fit fourth-degree age polynomials through the median wealth levels to obtain estimates for $w_{f}$ and $w_{m}$ for the entire range of age values, which, when normalized by a married couple's expected permanent income, generates our estimates of $\Lambda_{t+1, \iota} \cdot{ }^{25}$

In terms of altruism, we assume that spouses do not care about each other's future utility in the event of a divorce but that they place full weight on each other's utility in the event of widowhood. That is, we set $\lambda=1$.

\subsubsection{Asset returns}

As is common in the literature on life-cycle portfolio choice, we set the risk-free rate to $1.5 \%$ and the equity premium to $4 \% .{ }^{26}$ Equity returns are assumed to be distributed lognormally

\footnotetext{
${ }^{25}$ As an alternative approach to handling the merging of assets, we also estimated the median change in wealth due to marriage using panel data in the PSID and the HRS. We ran median regressions of the change in log financial wealth on an indicator variable for transitioning to marriage and other time-varying household characteristics. The estimated effects of marriage on wealth range from a low of about 0.2 for divorced males in the PSID to about 1.7 for divorced females in the HRS, with most values in the range of 0.5 to 1 . We solved the model assuming that transformed versions of these estimates governed the changes in wealth due to marriage across all age and education groups. While the results not surprisingly differed from the ones reported in our paper, they generated similar qualitative predictions in the sense that the simulated changes in savings and portfolio allocations due to marriage and children moved in the same direction and with similar orders of magnitude.

${ }^{26}$ Yao and Zhang (2005), Cocco et al. (2005) and Gomes and Michaelides (2005), for example, choose an equity premium of $4 \%$ and a risk-free rate of $2 \%$. We choose a slightly lower risk-free rate to match the long-run return on short-duration U.S. Treasury Bills, estimated to fall between $1 \%$ and $1.5 \%$. Mehra and Prescott (2008), for example, estimate the real return on short-maturity Treasury bills (and equivalent securities before 1931, when Treasury bills were introduced) to be $1.31 \%$ in the period $1889-2005$. The standard assumptions about risk aversion (i.e., a CRRA coefficient between 1 and 5) adopted in the literature
} 
with the possibility of correlation between returns and permanent income. As in Campbell and Viceira (2002), we set the standard deviation of annual equity returns to $15.7 \%$ and choose a baseline correlation coefficient between equities and permanent income of 0.15 (as in Cocco et al. (2005)). Given the importance of this correlation for the stock allocation decisions of younger workers, we also experiment with alternative values of this parameter.

\subsubsection{Life insurance}

Following Fischer (1973), we assume that households can purchase one-period term life insurance each period they are alive, regardless of marital status. As a simplification, we assume that married couples only purchase insurance for the husband, but that singles of either gender can buy life insurance that pays out to their children. Insurance is assumed to be actuarially fair, so that the face value of life insurance in present value terms always equals the premium divided by the probability of mortality for the individual purchasing the plan: $F V_{t}=Z_{t} /\left(1-p_{t+1, \iota}\right)$, and the payout in period $t+1$ is $R Z_{t} /\left(1-p_{t+1, \iota}\right)$. Finally, we do not allow households to purchase insurance in period $T-1$ since they will die with certainty in the following period. ${ }^{27}$

\subsection{Children}

\subsubsection{Births, Timing, and Spacing}

We need to specify how children are "born" in the model, how they are spaced, and what they imply for college expenses and child support payments. We assume that children are born stochastically, with probabilities that depend on age, education, and marital status. For tractability, we assume: (1) that mothers cannot give birth after age 40, (2) that females give birth to no more than 4 children in either the "early" or "late" periods, (3) that children born within each period are evenly spaced two year apart, regardless of the actual spacing

on life-cycle consumption generate $100 \%$ stock allocations for a risk premium that matches the long-run U.S. average of $6 \%$ (Campbell et al., 1997). A risk premium of $4 \%$, in conjunction with a relatively high coefficient of relative risk aversion of 5 , delivers the more interesting case of an interior allocation decision.

${ }^{27}$ The assumption that households purchase one-year term policies is obviously at odds with the term lengths of most life insurance policies in the U.S., which tend to fall between 10 and 30 years. The reason we do not model longer-term policies is that it would require that we introduce a computationally expensive state variable: the remaining duration of the term. In addition, it is not clear that longer term lengths would make an important difference in our model. In an economy with complete, and economically fairly priced life insurance, the price of an actuarially fair 30-year term policy would be equivalent to the present value stream of prices associated with buying one-period life insurance for each of the 30 years separately. Thus while there may be interesting issues related to the indivisibility of longer-term policies (such that a household would value the option not to be insured in some years), there is nothing fundamentally problematic with modeling a one-period term policy.

An additional concern with our formulation is that real-world insurance pricing is generally not actuarially fair, with average loads of 1.5-2 (Eisenhauer and Halek, 1999). We do not model these loads, however, because they imply much lower holdings of life insurance than we observe in the data. 
generated by realizations of the stochastic process, and (4) that the age of the mother when the first child is born is determined by the number of children and whether the first birth was early or late - early if the first child is born when the mother is younger than 30, and late if the first child is born when the mother is 30 or older. ${ }^{28}$

The ages of the children are determined by the age of the mother at the first pregnancy in each period, early or late. We assume that the mother has the first child in the early period at age 27 if just one child is born in that period, 26 if two children are born, 25 if three are born, and 24 if four are born. For late births, we assume that the mother is 34 if one child is born in the late period, 33 if two children are born in that period, 32 if three are born, and 31 if four are born. ${ }^{29}$

We calibrate the birth probabilities using fertility data published in a U.S. National Center for Health Statistics report (1997). The report publishes fertility rates by race, education, and marital status for the age brackets. We construct fertility probabilities for ages $20-40$ by fitting a third-degree polynomial through the reported probabilities (evaluated at the median age in each bracket). The resulting process produces an average number of children per household of about 1.7 for all three education groups, which is slightly lower than the value of 1.8 for non-Hispanic white women reported in the 2000 U.S. Census (Bachu and O'Connell, 2001).

\subsubsection{College}

We assume that all children attend college from age 18 to 22. Although this overstates college attendance rates in the U.S., it is actually consistent with most parents' expectations. A recent analysis by the National Center for Education Statistics, for example, showed that "[a]bout 9 in 10 students (91 percent) in grades 6 through 12 had parents who expected them to continue their education beyond high school" (Lippman et al., 2008). ${ }^{30}$ Our simplifying assumption that all children attend college implicitly acknowledges that we know little about the process and timing of parents' expectations regarding college expenses.

\footnotetext{
${ }^{28}$ The first two assumptions limit the number of children in the state space. The third assumption eliminates the need to keep track of an enormous number of potential birth spacings. The final assumption introduces some uncertainty about the children's ages, without requiring us to keep track of the mother's age at first birth. If, alternatively, we allowed children to be born at all ages between 20 and 40, we would multiply the state space (assuming no multiple births) by $2^{21}$, the number of unique binary strings with a length equal to the number of child-bearing years (ages 20-40).

${ }^{29}$ For example, suppose that two children are born in the early period and one child is born in the late period. When the mother is 45 years old, the children will be ages $11(=45-34), 17(=45-26)$, and 19 $(=45-26+2)$. We also experimented with different spacing and timing rules and found that our results are robust to alternative specifications.

${ }^{30}$ The report based its findings on data from the 2003 Parent and Family Involvement in Education Survey. Among the students whose parents expected them to pursue education beyond high school, about 71 percent had parents expecting them to complete a bachelors degree or higher. The remaining 29 percent had parents expecting them to complete "some post-secondary schooling."
} 
We model college expenses as a fraction of permanent income. Turley and Desmond (2006) compare the amount that married and divorced parents spend on college for their dependent children and find that married couples spent about $9 \%$ of income per year on each child's college education, while divorced parents spent about $7 \%$ of income. Except at very low income levels (below $\$ 20,000$ ), they find that the income share of college costs is relatively constant across the income distribution for married couples. For divorced parents, in contrast, the share of college costs rises substantially at higher levels of income (above $\$ 40,000){ }^{31}$ For simplicity, we assume that married couples and divorced parents spend identical fractions of permanent income on college expenses for each child. Given the rise in college costs since the Turley and Desmond study, we assume that parents spend $10 \%$ of permanent income per year on college costs for each child.

\subsubsection{Child support}

We model child support after the income sharing formulas adopted by most states. ${ }^{32}$ We assume that the non-custodial parent is male and that he must pay a percentage of permanent income in child support as long as the child is under 18. The percentages are taken from the State of Wisconsin's child support guidelines: 17 percent for one child, 25 percent for two children, 29 percent for three children, 31 percent for four children, and 33 percent for five or more children. ${ }^{33}$ In addition, we make the following three assumptions: (1) that the ratio of the male parent's income to the female parent's income is the same for all couples of a given age and education, and (2) that remarriage is assortative along the dimension of children (e.g., a man supporting two children from a former marriage will remarry a woman receiving child support for two children from her former spouse), and (3) that any children born out of marriage result in child support payments for men and child support receipts for women.

\footnotetext{
${ }^{31}$ Turley and Desmond proffer several theories to explain the rise in the share for divorced parents. One explanation they put forth is that higher income divorced parents were more likely than lower income divorced parents to interpret the survey question as asking about the combined contribution from both parents, including the ex spouse. If this is the case, it is not clear whether higher-income divorced parents actually spend a higher fraction of income on college expenses.

${ }^{32}$ See Bartfelt (2000) and Roberts (1994) for a discussion of the evolution of federal and state guidelines for child support. Child support guidelines vary across states, but the majority adopt a variant of "income sharing," which generally takes two forms. The first, the percentage-of-income method, links child care to a percentage of the non-custodial parent's income, with no adjustment for the income of the custodial parent. The second, the income shares method, assesses child support obligations according to the share of the combined custodial and non-custodial income. About 33 states have adopted the income shares approach, while about 13 states have adopted the percentage-of-income method.

${ }^{33}$ The State of Wisconsin's child support guidelines, the first implementation of the percentage-of-income method, were based on calculations of child costs from the Child Support Project of the Institute for Research on Poverty at the University of Wisconsin at Madison.
} 


\subsubsection{Equivalence scales and children}

Following Scholz et al. (2006), we adopt the scale factor recommended by Citro and Michael (1995): $n_{t, g, i}=(A+0.7 K)^{0.7}$, where $A$ and $K$ denote the number of adults and children living at home in period $t$. As discussed in Citro and Michael (1995), this formulation allows the equivalence scale to distinguish between household composition effects (the different consumption requirements of adults relative to children) and economies of scale.

\subsubsection{A simple example of how marital changes affect household resources}

Given that the model has a number of "moving parts," it might be helpful to consider a simple example of how changes in marital status affect household resources in the model. Table 3 displays the changes in permanent income, child support, wealth, and equivalence scales due to transitions to marriage, divorce, and widowhood for 40-year-olds with a 13year-old child. The man and the woman in the example each have permanent incomes of $\$ 25,000$ before a transition to marriage, while the married couple has $\$ 50,000$ in permanent income, $\$ 200,000$ in initial wealth, and a life insurance policy for the husband with a death benefit of $\$ 100,000$.

The changes in permanent income with marriage reflect assortative matching; men in the model always marry women with lower incomes, and the difference is determined by the ratios of their relative income profiles (shown in Figure 1). Wealth increases with marriage according to the median levels held by single men and women in the data (see Section 3.1.5); it divides equally in the case of divorce; and it rises for the woman in the event of widowhood because of life insurance. Child support obligations and receipts are washed out in marriage, and the change in equivalence scales reflects whether children are living at home following a marital transition.

\subsection{Mortality, marriage, and divorce}

Household heads of each gender must occupy one of five states at the beginning of each age. They can be married, divorced, widowed, never married, or deceased. We estimate transition probabilities between these states as a function of age, marital status, and gender using reported coefficient estimates from the Urban Institute's Model of Income in the Near Term, Version 5 (MINT5). Originally designed for the Social Security Administration's (SSA) Division of Policy Evaluation, MINT5 estimates income and demographic processes using pooled data from the 1990-2001 Surveys of Program Participation (SIPP) and SSA files of past earnings and benefits.

To model transitions across all demographic states, we need information on the probabilities of divorce, marriage, and mortality. The MINT5 report (Smith et al., 2007) presents 
estimates of continuous-time hazard models for separate divorce and marriage equations for men and women. The MINT5 report also calibrates the original MINT's mortality hazard estimates to match the Social Security Office of the Actuary projections. We base our transitions on the pooled-sample estimates reported in Table 2-1 (marriage hazard for males), Table 2-2 (marriage hazard for females), Table 2-3 (divorce hazard for males), Table 2-4 (divorce hazard for females), and Table 2-5 (mortality hazards for males and females). ${ }^{34}$

Using our estimated marriage, divorce, and mortality functions, we then construct separate demographic transition matrices for male- and female-headed households. For consistency, we require that the probability of divorce within a married couple is the same for each spouse, so that they agree on the odds of separation. We do not, however, adjust our matrices to match the number of spouses of each type at every age as in Hong and Ríos-Rull (2006). In this, and in all other respects, our model economy represents only a partial equilibrium.

\subsection{Preference specification and moment-matching procedure}

In our baseline simulations, we set the coefficient of relative risk aversion $\rho$ equal to 6 , which is well within the range of typical values assumed in studies of portfolio choice. ${ }^{35}$ Convention provides less guidance, however, for the bequest specification. Some studies choose bequest parameters to match data on the transfer wealth share in the economy and the distribution of bequests across different income categories (De Nardi, 2004). Others use bequests to match mean or median wealth holdings among households (French, 2005; French and Jones, 2004a; Cagetti, 2003). Our interest in bequests lies in their effect on life-insurance decisions during the working life and wealth spend-down patterns in old age.

\footnotetext{
${ }^{34}$ We make several adjustments to the MINT5 estimates in the divorce, marriage, and mortality equations. The mortality equations for males and females in MINT5 include covariates for age, education, marital status (never married, divorced, and widowed), indicators for disability status, and a measure of the household's deviation from their predicted income. Our mortality function includes most of the coefficient estimates, but we omit the disability adjustment and the measure of permanent income since it is unclear how to map the MINT5 definitions of these concepts into our model. Still, the MINT5 estimates allow for differential mortality along the dimensions of gender, marital status, and education, the last of which is strongly predictive of our model's notion of permanent income.

We make more extensive adjustments when converting the marriage and divorce estimates into functions appropriate for our model. The most significant of these involve the issue of duration. The MINT5 specifications assume that the likelihood of marriage depends on the number of years a person has been unmarried, and that the likelihood of divorce depends on the number of years a person has been married. Keeping track of this information in our model would require carrying around a pair of computationally expensive state variables for the appropriate durations. Instead, we assume that previously married individuals have been unmarried for 5 years (never married individuals are assumed to have been unmarried in a number of years directly proportionate to their age) and that married individuals have been married for 10 years. We also experimented with assumed durations of 3 and 15 years and found that the resulting change in the probabilities of divorce had little effect on households' responses to family shocks.

${ }^{35}$ For example, Cocco et al. (2005) set the coefficient of relative risk aversion to 10, which is at the upper end of the range, while Cocco (2005) and Gomes and Michaelides (2005) each assume a value of 5.
} 
Because the ratio of wealth to future income plays such a fundamental role in portfolio decisions, it is important to match the empirical values of this ratio as closely as possible.

We focus on matching wealth levels, but we do not calibrate our model to match observed patterns of stock allocations. Conditional on stockmarket participation, studies of optimal portfolio choice, including ours, find that simulated allocations tend to decline during the working years, which is at odds with the age path of stock shares observed in the data. ${ }^{36}$ The lack of an age trend is apparent in both the PSID and the HRS. Table 4 reports the average shares for different age and marital status groups in the PSID (for ages 20-50) and the HRS (for ages 50-80), conditional and unconditional on holding positive amounts of stock. Apart from an increase in the shares at age 50, which reflects the higher average stockholding in the HRS, the shares change relatively across age and marital status categories. The average shares conditional on participation, for example, range from 43-50 percent in the PSID and from 55-60 percent in the HRS.

We select the values of the discount factor $\beta$ and the bequest parameter $b$ that provide the closest fit between our simulated cash on hand levels and the values observed in the data. Similar structural estimation exercises can be found in Gourinchas and Parker (2002), Cagetti (2003), and French (2005). ${ }^{37}$ We focus on the discount factor and the bequest parameter, rather than the coefficient of relative risk aversion, because the typical estimates of risk aversion (0.50-4.25) generate optimal allocations in the risky asset that are concentrated at $100 \% .{ }^{38}$ Further, because higher degrees of patience and a stronger bequest motive each increase the wealth to income ratio toward the end of life, the two parameters are partial substitutes in terms of identifying parameters.

Let $\Omega=\{\beta, b\}$ denote the pair of parameters used to match the empirical medians. We base our estimate on medians, rather than means, because they are more appropriate for matching the savings behavior of the typical household within each education and marital status group. For each age bracket $a_{i} \in\left\{a_{1}, a_{2}, \ldots, a_{n}\right\}$ and marital status

\footnotetext{
${ }^{36}$ Empirical studies of life-cycle allocations generally find no clear evidence of an age trend in portfolio shares after controlling for year effects (see, e.g., Ameriks and Zeldes (2004) and Poterba and Samwick (2001)). The problem of matching empirical allocation paths, conditional on stockmarket participation, remains even after controlling for endogenous housing investment. In his study of housing and portfolio choice, Cocco (2005) shows that the age pattern of housing investment can go a long way toward matching the level of unconditional stockholding in the PSID data. Conditional on participation, however, their model still predicts higher-than-observed allocations in the risky asset.

${ }^{37}$ Gourinchas and Parker (2002) use the simulated method of moments to estimate the combination of risk aversion and the discount rate that match the average consumption profiles for different education and occupation groups. French (2005) structurally estimates the profiles of labor supply and assets to study retirement behavior in the presence of income and health uncertainty. Our estimation exercise is closest, however, to Cagetti's (2003), which estimates the value of the discount factor and risk aversion that match median net wealth profiles in the PSID and the Survey of Consumer Finances (SCF).

${ }^{38}$ It should be noted that even though our choice of risk aversion is higher than the values estimated in the studies, Cagetti (2003) finds that increasing the coefficient of relative risk aversion from the estimated value of around 4 to a higher value of 6 has little effect on the simulated wealth paths.
} 
$j \in\{$ married, single male, single female $\}$, let $\hat{M}_{i}^{j}$ be the median empirical level of cash on hand, and let $M_{i}^{j}(\Omega)$ be the median level in the simulations. For each education group, we search over $\Omega$ pairs to solve:

$$
\Omega^{*}=\underset{\Omega}{\operatorname{argmin}} \sum_{j=1}^{3} \sum_{i=1}^{n}\left(\frac{\hat{M}_{i}^{j}-M_{i}^{j}(\Omega)}{\hat{M}_{i}^{j}}\right)^{2} .
$$

In practice, we consider 5-year age brackets from ages 20 to 95 and search over a discrete set of $\Omega{ }^{39}$ For the younger age brackets, up to age 65 , we compute the median wealthto-income ratios using the PSID wealth supplements. For the rest, we use the 1992-2006 waves of the HRS.

Figure 2 compares the empirical median values of cash on hand (net wealth plus current income) with the simulated levels from models solved with the pairs of discount factors and bequest motive that minimize the criterion function above. For high school graduates, we estimate $\beta=0.9215$ and $b=3.25$, with a sum of squared deviations equal to 2.57. For college graduates, we estimate $\beta=0.9050$ and $b=4.00$ with a sum of squared deviations equal to 4.81. As shown in the figure, the fit between the simulated ratios and the data is quite close for most of the life cycle but deviates somewhat toward the end of life. The imperfect match at the tail end of life is due to the fact that we are simultaneously matching wealth levels for three separate household types. Thus, for example, while we underpredict wealth accumulation in retirement for single men, we overpredict it for single women.

Our estimated values of $\beta$ are on the low end of the estimates in the literature (0.930.96 in Gourinchas and Parker (2002), and 0.92-0.99 in Cagetti (2003)). The reason for the difference in estimates can be attributed to the fact that we assume a relatively high degree of risk aversion. As Cagetti (2003) notes, higher degrees of risk aversion induce households to save more for precautionary purposes, and this implies a lower estimate of patience to match the same median wealth to income ratios.

\section{Optimal decisions about savings, life insurance, and port- folio choice}

How do family shocks affect optimal savings, life insurance, and portfolio choice? In this section, we address this question by first examining how the average levels of these variables (across a large number of model simulations) differ by marital status, education, gender, and children. We find that the average age profiles differ substantially by marital status and children, which we interpret as preliminary evidence that family shocks can indeed

\footnotetext{
${ }^{39}$ We choose a grid of $\beta$ values spaced 0.0005 apart and a grid of $b$ values spaced 0.25 apart.
} 
have a large effect on household saving decisions. Just looking at average profiles does not, however, provide a clean experiment to identify the direct effects of marital status transitions and children on optimal saving and portfolio choice. To analyze the direct effect of these transitions, we perform two exercises. In the first we show how the average portfolio allocation of a typical household - typical in terms of demographics, wealth, and incomechanges in response to a given marital status transition. In the second we examine the decision rules directly and trace out the portfolio responses to different family shocks across a range of wealth-to-income levels. The results from both sets of experiments indicate that changes in marital status can lead to large adjustments in savings and portfolio choice.

\subsection{Life cycle profiles}

As a benchmark parameterization for each education group, we set the coefficient of relative risk aversion $\rho=6$ and the correlation between stock returns and the permanent component of income $\operatorname{corr}_{r, y}=0.15$. The solution to the model consists of a set of interpolated policy rules for life insurance, consumption, and portfolio allocation, which are each functions of age, marital status, the number of children born in the early and late periods, and the ratio of cash on hand to permanent income. ${ }^{40}$ With the decision rules in hand, we then generate 50,000 life histories reflecting independent realizations stock returns, permanent and transitory income, marital status, births, and deaths. We initialize the histories by randomly assigning $15 \%$ of the households to be married at the beginning of the working portion of the life cycle, which approximates the initial distribution implied by our marital status transition process. Finally, we solve and simulate the model for each of the three education groups but focus the discussion of our results on high school and college graduates since the qualitative results for the bottom two groups are quite similar.

Figure 3 displays the average life cycle profiles of consumption, cash on hand, and the face value of life insurance (the death benefit) for male-headed households with a high school degree (left plot) and for those with a college degree (right plot). Both profiles show a similar pattern of savings. Wealth builds up gradually until around age 50, after which point it accelerates slightly to a peak near retirement age. The upturn in saving occurs right

\footnotetext{
${ }^{40}$ We solve the model backwards starting from the final period $T$ with a 60 -point grid of $x_{T}$ spaced according to a triple exponential that places more density on lower values of cash on hand (see Carroll, 2007). Given pairs of $c_{T}^{*}$ and $x_{T}$, we construct a linear interpolating function for the final period's optimal consumption problem. Next, we discretize end-of-period savings $a_{t}$ into another 60-point grid, also exponentially spaced. For each value of $a_{t}$, we can solve for optimal life insurance, portfolio allocation, and consumption using the first-order-conditions given by equations (12), (14), and (15). Expectations of returns and income are approximated using 10-point Gauss-Hermite quadrature, where we allow for correlation between equity returns and the permanent component of labor income. Given $a_{t}$ and an optimal pair of $c_{t}^{*}$ and $z_{t}^{*}$, we can endogenously recover the level of $x_{t}$ through the definition of end-of-period savings $a_{t}=x_{t}-c_{t}-z_{t}$. The solution to the life-cycle model then consists of interpolated decision rules $\mathbf{c}\left(x_{t}\right), \mathbf{z}\left(x_{t}\right)$, and $\varsigma\left(x_{t}\right)$ for each age, marital status, gender, and number of children born in the early and late periods.
} 
around the age at which children are exiting the household and finishing post-secondary schooling. Households draw down their wealth in retirement but maintain relatively high savings all the way to the maximum age of 100, reflecting the importance of the bequest motive for households with children. This pattern of an accelerating build-up of wealth followed by a slow drawdown in retirement is even more pronounced for college graduates, who have, on average, more hump-shaped income profiles and stronger bequest motives.

The pattern of wealth displayed in the two panels of Figure 3 follows naturally from the age pattern of consumption and life insurance purchases. Household consumption is humpshaped for both education groups and displays some small wrinkles around the ages at which children leave home, when total consumption demand is lightened due to a reduction in the equivalence scales. The acceleration of savings in the 15 years before retirement occurs as consumption tapers off relative to income (not shown) and life insurance purchases decline.

Life insurance is purchased predominantly by younger married couples, who have the most future income at stake in the event of an early and unexpected death. As these couples age and accumulate assets, however, the concern becomes less that the death of a spouse will reduce future income and more that the couple will outlive its financial assets, making life insurance less and less attractive. For high school graduates, the average simulated face value of life insurance peaks around age 35 at $\$ 110,000$ for the combined sample of all households and at $\$ 153,050$ for married couples, while for college graduates the peak occurs a touch later in life at about $\$ 137,350$ for all households and $\$ 190,060$ for married couples. ${ }^{41}$ Hong and Ríos-Rull (2006) report data on life insurance from Stanford Research Institute and find that life insurance holdings for married couples in the U.S. peak around age 45 at $\$ 170,000$ (in year-2006 dollars), a bit later than our model predicts but roughly the same magnitude.

The role of life insurance, which in part is purchased to protect desired bequests, raises the question of how children affect wealth accumulation and portfolio choice over the life cycle. On the one hand, children lead to an increase in household expenditures, private transfer payments (child support), and college expenses and thus are capable of exhausting a substantial portion of household resources. On the other hand, children might also promote saving, with younger households preparing for future college expenses and older households protecting desired bequests.

Figure 4 shows how the presence of children affects the average simulated age profiles of cash on hand and portfolio shares for high school and college graduates. The solid red lines in the figure show the average profiles for households without children; the dashed blue lines show the profiles for households with at least one child. The wealth profiles in the top

\footnotetext{
${ }^{41}$ Life insurance holdings for singles are much lower $-\$ 28,600$ and $\$ 42,620$ for high school- and collegeeducated men, and $\$ 13,800$ and $\$ 6,760$ for high school- and college-educated women - reflecting the absence of a spousal beneficiary and the lower average number of dependents.
} 
two panels reflect the competing saving effects of increased desired consumption and the bequest motive. For both education groups, households with children tend to accumulate substantially less savings during the working life, but their slower rates of drawdown in retirement leave them with a larger amount of wealth as they age.

The bottom two panels of Figure 4 show that children also affect the age profiles of portfolio shares. During the working years, households with children tend to place about 5-15 percentage points more of their wealth in stocks relative to households without children. In retirement, however, the average portfolio shares for households with and without children cross and diverge markedly with age, reflecting the increasing importance of preserving bequests.

\subsection{Effect of marital status and children on average life cycle profiles}

The importance of bequests and earnings profiles in shaping savings and portfolio decisions is consistent with the findings in previous studies. ${ }^{42}$ The novelty of our analysis, however, resides in showing how these decisions are affected by marital status and children. We begin by comparing the average portfolio shares across different categories of age, gender, education, marital status, and children. The average simulations highlight the heterogeneity in portfolio allocations by household type, but they are somewhat limited in that they say nothing about how individuals respond at the time of a shock, an issue we turn to in the last two sections of the simulation results.

Table 5 reports the average portfolio shares for different combinations of age, gender, education, marital status, and children. Perhaps the first thing to notice about the table is the considerable heterogeneity in the shares across household types. Single men hold more of their wealth in stock than single women; college graduates tend to have more conservative allocations than high school graduates; working-age households with children hold more stock than those without children; and there are large differences in the average shares across marital status categories. Within each age bracket, many of the average shares differ by as much as 15 to 25 percentage points. Just looking at the average portfolio shares for all households therefore masks a fairly large source of variation across household types.

\footnotetext{
${ }^{42}$ Cocco et al. (2005) and Gomes and Michaelides (2005) trace the lifecycle profiles of consumption, wealth, income, and portfolio shares and find that households tend to move toward a safer allocation as they approach retirement. What happens to the simulated portfolio share after retirement depends on the relative importance of income shocks, bequest motives, and the pace of wealth drawdown. Gomes and Michaelides (2005), for example, finds that the share rises slightly and then falls in retirement, a result that stems from the absence of income uncertainty in retirement and the growing importance of the bequest motive (they select a bequest parameter $b=2.5$ ) at later ages. Cocco et al. (2005), on the other hand, find that the optimal share tends to rise throughout retirement in their benchmark specification with no bequest motive. In the absence of a bequest motive, the increasing rates of wealth drawdown with age make asset return shocks less important for future consumption needs.
} 
Another pattern shown in the table is the striking asymmetry in the effects of divorce and widowhood on the portfolio shares of men and women. Comparing the average shares for married couples with those for divorced men and women, we can see that divorce is associated with a fairly large increase in the average shares of men but either a decrease (as in the case of college graduates) or only a slight change (as in the case of high school graduates) in the average shares of women. The difference in the impact of divorce is largely due to the relative changes experienced by men and women in wealth, future income, custody, and child support. While each spouse sees an immediate reduction in household wealth of $55 \%$ (the 50/50 division plus legal fees) in the event of a divorce, men experience a smaller decrease in future household income relative to women, and they are relieved of custodial responsibilities for any children. Child support obligations offset part, but not all, of the gender imbalance in committed expenditures and future income.

In terms of widowhood, the average shares indicate that the loss of a spouse is a far more important event for the shares of women than for those of men. For example, while the shares of widowed females with children are about 15 percentage points lower than the shares of married couples with children, there is almost no difference in the shares of widowed and married men. The gender difference in the response to widowhood is largely the result of three factors that increase women's exposure to market risk relative to men's. First, since couples purchase life insurance to protect only against the risk of losing the husband's earnings, women, but not men, generally gain wealth with the loss of a spouse. Second, in addition to experiencing an increase in wealth, women also face a sharper decrease in expected future household income, with no offsetting child support payments. Finally, women also have a larger actuarial risk relative to men of outliving their wealth.

Differences in portfolio shares by household type depend fundamentally on the average levels of household wealth. For example, the average shares married couples with and without children tend to diverge during the working years and then converge in retirement, a pattern mirrored by the evolution of wealth shown in Table 6. Married couples with children head into retirement with substantially less wealth than childless couples $(\$ 587,600$ vs. $\$ 735,600$ for college graduates). By ages $75-85$, however, the strength of the bequest motive reverses this relationship, and couples with children end up holding more wealth. The slow pace of wealth drawdown among couples with children means that an increasing amount of their future consumption and bequests must be paid for out of wealth, which is subject to market volatility, rather than income, which is not. Similar patterns in the portfolio allocations and wealth levels can be seen for other marital status groups as well.

Naturally, the response of portfolio choice to demographic shocks depends on much more than just the change in the level of savings. Other factors include changes in the volatility of income, increases or decreases in the equivalence scales, and expectations about future 
changes in marital status and children. To get a closer look at households' responses to change in marital status, we now examine optimal savings behavior at the time of the shock.

\subsection{Effect of changes in marital status and children on average portfolio allocation}

\subsubsection{Changes in simulated portfolio shares}

Table 7 reports the one-period detrended difference in portfolio shares in response to a change in marital status. For the baseline parameterization $\left(\rho=6, \operatorname{corr}_{r, y}=0.15, \beta=\right.$ 0.9215 and $b=3.25$ for high school; $\beta=0.9050$ and $b=4.0$ for college), the table displays the percentage-point change in the portfolio shares relative to the trend change for each marital status category. The calculations detrend the changes in portfolio choice because we are interested in the average change relative to the "typical" change in that year. Thus if we are interested in the effect of divorce on the portfolio shares of 55-year-old men, we calculate the average simulated change in the shares for men immediately following a divorce and subtract from that the average change in the shares of those who remained married. ${ }^{43}$

Starting with the effects of divorce in Table 7 , we can see that age, gender, education, and children all have important interactions with the impact of marital status on portfolio allocations. Particularly notable are the strong differences by gender and the presence of children. Among working age households, men respond to divorce by sharply increasing their shares in stock by an average of about 15 percentage points, while women respond by moving to a safer allocation. The presence of children, however, dampens the reponse of men's portfolio shares to divorce by as much as 50 percent. For women, the interaction between children and divorce is more complicated. Children limit the decline in the shares of younger women (i.e., ages 30-40), have almost no effect on the shares for ages 45-55, and lead to a slightly larger decline for ages 55-65. In contrast to divorced men, for whom (in the model) children primarily represent a loss of income due to child support payments and larger future outlays for college, women are assumed to retain custody of the children and therefore experience an increase in desired household consumption that largely offsets the receipt of higher income in the form of child support.

Widowhood triggers dramatic adjustments in the average shares, particularly among working-age women, who reduce their shares by 10 to 37 percentage points. At more advanced ages, widowhood comes as less of a surprise, and the portfolio adjustments are consequently smaller in magnitude. At all ages, widowhood leaves surviving spouses with,

\footnotetext{
${ }^{43}$ Note that this is only an approximation of the "typical" effect of a marital status transition since the typical change is itself a function of wealth and income. To obtain a more accurate picture of the wealth transitions, we examine below the changes in the decision rules themselves, which allows us to identify more precisely the direct impact of marital status on the optimal portfolio share.
} 
at least, the full amount of household savings, which tends to magnify the impact of market risk on future consumption and therefore utility. This effect is amplified in the case of working-age women, who actually see an increase in wealth due to the life-insurance payout. As with divorce, the impact of widowhood depends on the presence of children, varying by as much as 8 percentage points in the case of working-age women.

Divorce and widowhood are not the only family shocks that can induce large changes in the optimal portfolio share; transitions to marriage matter as well. Movements from divorce to marriage generally trigger changes in the portfolio shares in the opposite direction of those caused by transitions to divorce. Thus, for example, 55-65-year-old male high school graduates increase their shares by about 16 percentage points following a divorce, and they reduce their shares by about 14 percentage points when they remarry. This is not always true for the case of widowhood. For example, while women tend to drastically reduce their shares in response to widowhood, they make only minor adjustments in the event of remarriage. In contrast to widowhood, which effectively holds wealth constant but reduces future income, remarriage leads to a partly offsetting increase in both wealth and income.

\subsubsection{Changes in portfolio shares implied by decision rules}

The change in the average portfolio shares at the point of a marital status transition tells us about the response of a typical household, with a typical amount of wealth, income, children, and asset returns. It is also interesting, however, to study the underlying mechanism governing the response to family shocks - the direct responses implied by the decision rules themselves. The decision rules allow us to analyze the exact change in the optimal portfolio share for individuals with a particular set of state variables and to show how those decisions vary across the full range of cash on hand to income ratios.

Let $\varsigma_{t, \iota}\left(x_{t}\right)$ be the optimal portfolio decision rule for a household of type $\iota$. In the following experiments, we will assume that the return on risky assets, the permanent income shock, and the transitory income shock are all equal to their expected values, so that $R_{t+1}=\varsigma_{t} \mathbf{E}_{\mathbf{t}} R_{t+1}^{e}+\left(1-\varsigma_{t}\right) R=\bar{R}$, and $N_{t, \iota}=\Theta_{t, \iota}=1$. The evolution of $x_{t}$ is given by

$$
x_{t+1}=\bar{R}\left[x_{t}-\mathbf{c}_{t, \iota}\left(x_{t}\right)-\mathbf{z}_{t, \iota}\left(x_{t}\right)\right] / G_{t+1, \iota^{\prime}}+\left(1-h_{t+1, \iota^{\prime}}\right)+\Lambda_{\iota, t+1},
$$

where $\mathbf{c}_{t, \iota}\left(x_{t}\right)$ and $\mathbf{z}_{t, \iota}\left(x_{t}\right)$ are the decision rules for consumption and life insurance.

A change in marital status can lead to a division or merger of assets (in which cases $\Lambda_{t+1, \iota^{\prime}} \neq 0$ ), and it can lead to a change in trend permanent income, $G_{\iota^{\prime}, t+1}$. Even in the absence of a marital transition, there is likely to be a change in portfolio choice due to the evolution of cash on hand relative to income, housing costs, and so on. We control for these trend changes in portfolio choice by first computing the time difference in $\varsigma_{t, \iota}\left(x_{t}\right)$, allowing 
for a marital transition, and then subtracting the time difference in $\varsigma_{t, \iota}\left(x_{t}\right)$, assuming $\iota=\iota^{\prime}$. The result, which we denote $\Delta \varsigma$, represents the change in the optimal portfolio share that is strictly due to a change in marital status.

What do the decision rules imply about the effect of a transition from marriage to divorce or widowhood? Figure 5 displays the values of $\Delta \varsigma$ for childless male and female high school graduates of select ages across a range of cash on hand to income ratios, $x_{t}$. The results for college graduates are shown in Figure 6 . In the top panels, $\Delta \varsigma$ is the change in the optimal portfolio decision triggered by divorce, while in the bottom panels it represents the change due to widowhood. At sufficiently low levels of $x_{t}$, there is no change in the portfolio shares because the optimal amount is stuck at a corner allocation of $100 \%$. As the level of $x_{t}$ rises beyond the threshold, however, the changes in the optimal shares increase and then taper off toward zero, reflecting the curvature of the decision rule as a function of wealth $\left(\varsigma_{x}<0\right.$ and $\left.\varsigma_{x x}>0\right)$.

As with the changes in the average simulated shares, the decision rules show that divorce pushes the shares of men and women in opposite directions. Divorce induces a sharp downward adjustment in the shares of 30- and 45-year-old women of as much as 25 percentage points. (Approaching retirement, divorce induces a slight increase in the shares of women, reflecting the tendency for divorce to actually reduce women's overall exposure to financial risk by lowering the wealth to income ratio.) Men, in contrast, dramatically increase their shares in response to divorce. The impact diminishes with age and the level of wealth (for the same reasons it does for women), but all of the increases in the portfolio shares are in the range of 10 to 40 percentage points. As explained above, divorce tends to make men much less dependent on wealth to finance financial future consumption, because they no longer have to save to finance the expected consumption of a longer-lived, lower-earning spouse, and because they experience a relatively large decline in wealth relative to income.

At all ages, widowhood induces large declines in the optimal portfolio shares, with the largest movements for working-age women. In the bottom panels of Figures 5 and 6 , the portfolio shares for 45-year-old women drop by 10 to 40 percentage points, depending on the level of $x_{t}$. For ages 65 and 85, the decrease in the portfolio share in the risky asset is half to two-thirds as large. Middle-aged women are more sensitive to the loss of a spouse, primarily because the event comes as more of a surprise. The surviving spouse experiences a sudden drop in future income relative to wealth, and this in turn makes future consumption streams more sensitive to fluctuations in the rate of return on risky assets.

The decision rules indicate that the optimal share in the risky asset responds to changes in marital status. Figures 7 and 8 show how these responses depend on the presence of children. The top panels of the figures display the changes in the portfolio shares for 45-yearold males and females who have either no children (the solid red line) or three children (the 
dashed blue line). The bottom panels of the figures show how children alter the response to widowhood for 80-year-olds. The top panels show that, especially for men, children have a strong impact on the response of optimal portfolio shares to divorce. The presence of children dampens the increase in men's portfolio shares by as much as 20 percentage points, while it reduces the decline in women's shares by about 4 percentage points. The bottom panels indicate that children amplify the effects of widowhood and that they have a larger impact on the portfolio responses of men. Because of the differences in the survival probabilities between men and women, widowhood leaves men much closer to the age of leaving a bequest, which increases the attractiveness of a safer allocation. The predominant concern for widowed women, in contrast, is the loss of a larger stream of future income, which happens regardless of whether there are children.

In both the average simulations and the decision rule experiment, the magnitudes and even the signs of the response of portfolio choice to a change in marital status depend on all of the state variables in the model-age, education, wealth, income, children, and gender. Given the heterogeneity in responses, it is helpful to take a step back and ask what one can conclude about family shocks and optimal portfolio choice. At the broadest level, the results indicate that marital status transitions play an important role in savings and allocation decisions and that children can amplify or dampen these effects. More narrowly, the results show first that widowhood leads to substantially safer allocations for both men and women, with the strongest effects for women. Second, they show that divorce tends to reduce the shares of women and increase the shares of men, with magnitudes that depend crucially on the presence of children.

\subsection{Robustness and sensitivity analysis}

We test the sensitivity of our results to alternative assumptions about the coefficient of relative risk aversion and the degree of correlation between stocks and permanent income. Table 8 reports select changes in the average simulated portfolio shares in response to divorce and widowhood for men and women either in the middle of their working years (ages 4555 ) or in retirement (ages 75-85). The first columns of the table repeat the baseline case discussed above. The next pair of columns show what happens when we set the correlation between returns and permanent income to 0 . The columns titled "Low CRRA" show the results for a value of $\rho=4$, and the final columns titled "High CRRA" show the values for a value of $\rho=8$. For each of the specifications, we reestimate the values of $\beta$ and $b$ that minimize the squared distance between the simulated cash-on-hand levels and those in the data. $^{44}$

\footnotetext{
${ }^{44}$ The values of $\beta$ range from 0.8650 for college graduates with high risk aversion to 0.9650 for college graduates with "low" risk aversion. The values of $b$ range from 2.25 for high school graduates with low risk
} 
The results in the table show that the correlation between the risky asset and permanent income has only a small effect on the impact of family shocks on portfolio decisions. Few of the values in the table change by more than a couple percentage points when we remove the correlation, and they all share the same sign. Increasing or decreasing the coefficient of relative risk aversion, in contrast, generates larger differences in the response of shares to divorce and widowhood. But even here, none of the signs or magnitudes would alter the main story from the baseline simulation experiments.

\section{Empirical evidence on family effects}

Results from the model simulations predict that divorce and widowhood have a strong influence on the share of risky assets. To test this prediction, we take advantage of the panel dimension of the HRS and the PSID to estimate random-effects tobit regressions of the risky share on household characteristics and marital status. Despite the drawbacks of the random effects approach, ${ }^{45}$ we include the estimates to provide at least a broad picture of the empirical relationship between marital status and portfolio choice. For younger households (ages 20-70) we estimate regressions using the 1999, 2001, 2003, and 2005 wealth supplements in the PSID, while for older households (ages 60-90) we use the 1992-2006 waves of the HRS.

The dependent variable in the regressions is the stock share - the net value of stocks (directly-held, mutual funds, and investment trusts) divided by net financial wealth. ${ }^{46}$ We estimate separate regressions for men and women and for three different marital status categories: "Divorced" includes respondents who are either divorced or married; "Widowed" includes those who are widowed or married; and "Never-married" includes those who are either never-married or married. The regressions include controls for race, health status, wealth to income ratios (averaged over the sample periods), age, education, and year dummies. The variables of interest are the three marital status/education interaction dummies, the marginal effects estimates of which can be interpreted as the percentage point change in the stock share associated with a particular combination of marital status and education.

Table 9 reports the marginal effects estimates and standard errors (in parentheses) for the HRS regressions of older households, and Table 10 reports the estimates for the PSID

aversion to 4.25 for college graduates with high risk aversion.

${ }^{45}$ The random effects tobit specification generates unbiased estimates only in the special case where the unobserved effects, which are integrated out of the likelihood function, are uncorrelated with the observed effects. In our specification, worrisome sources of unobserved heterogeneity include risk aversion (potentially correlated with wealth, income, health, and possibly marital status), impatience, and financial sophistication. The infrequency of marital transitions leave us with insufficient information to precisely estimate fixed-effects or correlated random effects specifications.

${ }^{46}$ See Section 3.1.5 for a description of the data and the definition of net financial wealth. 
regressions of younger households. Beginning with the HRS results, the top lines of the Table 9 indicate that the portfolio shares in risky assets of divorced men and women are between 2.2 and 4.0 percentage points lower than those of married households, with the magnitudes depending mostly on education. The estimate on the divorce interaction for high school graduates is statistically significant at the 1-percent level, while the estimates on divorce for the other marital status/education interactions fall slightly below the 5-percent level of significance.

As with divorce, widowhood is also associated with a lower stock share in the risky asset. According to the estimates in Table 9, the effects of widowhood on the portfolio share range between 3 and 10 percentage points for respondents with a high school degree or below. For college graduates, however, the marginal effects are weakly positive for males and weakly negative for females. The final columns of the table report the estimates for never-married households, an under-populated group among the older households in the HRS sample. The marginal effects estimates on the never-married/education interaction dummies suggest that marriage is associated with larger allocations in the risky assets for all but female college graduates. Although the HRS estimates do not always share the same signs as those predicted in our model simulations, they do suggest that marital status may be an important factor in determining portfolio decisions, at least among the older households represented in the survey.

The PSID results, reported in Table 10, suggest that marital status may be important for the portfolio shares of younger households as well. Among high school graduates, divorce is associated with a (statistically insignificant) gain of about 2.5 percentage points in the risky share for males but a (statistically significant) decline of 6.3 percentage points in the share for females. The estimates for college graduates, in contrast, show little relationship at all between divorce and portfolio allocations of either men or women, which is consistent with potentially offsetting effects or, perhaps, measurement error. The final columns of Table 10 suggest that first marriage may indeed be important for portfolio choice, but not in the way our model predicts. According to the marginal effects estimates, male high school and college graduates hold 5-7 percentage points more of their portfolios in stocks compared with married households. For females the relationship between first marriage and the risky share is statistically close to zero for high school and college graduates and strongly and significantly negative for females with less than a high school degree.

The results in Tables 9 and 10 suggest that other variables that have an important effect in the model simulations matter empirically as well - though again, not always with the same direction of impact. The number of children living at home, for instance, is associated with about a 1-percentage point decline in the share of risky assets. In all of the regressions, the average ratio of cash on hand to income is positively and significantly 
related to the portfolio share, which contrasts with the model's predictions of a negative relationship between $x_{t}$ and the optimal share. ${ }^{47}$ Finally, the sign pattern on age and agesquared in the HRS and PSID regressions suggest that the portfolio share in stocks follows a hump-shaped pattern in the working life and then falls gradually in retirement. ${ }^{48}$

\section{Conclusion}

This paper finds that family shocks - sudden changes in resources and expectations induced by transitions in marital status and family composition - can lead to sharp adjustments in household savings and portfolio choice. We examine the role of family shocks by first analyzing simulation results from a life-cycle model of optimal saving, allocation, and life insurance, where households are subject to uncertainty about marital status and children. Results from the simulations indicate that family shocks can induce changes in optimal portfolio shares of over 30 percentage points, with typical changes in the range of 10 to 15 percentage points. We find that divorce and widowhood have particularly strong effects on allocations, and that these effects differ significantly by gender, as well as by the number and ages of children. Widowhood reduces the optimal share of stocks for both men and women, but the effects are especially pronounced for women. Divorce, in contrast, leads to sharp portfolio adjustments in opposite directions for men and women, with men moving to a riskier allocation and women to a safer one.

To test the empirical importance of marital status and children for portfolio choice, we estimate the effect of family shocks on the share of risky assets using data from the HRS and the PSID. The estimation results provide evidence that family shocks matter empirically, as well as in the model simulations. Panel tobit regressions generate marginal effects estimates on marital status indicators for divorce, marriage, and widowhood in the neighborhood of 5 to 10 percentage points. The signs of the estimates do not, however, always agree with the direction of the impact predicted by the model.

The literature on optimal portfolio choice over the life cycle has focused on the roles of housing costs, assumptions about preferences, stockmarket participation costs, and background risks due to uninsurable labor income. This study suggests that marital status

\footnotetext{
${ }^{47}$ This inconsistency is found in most studies of optimal portfolio choice over life-cycle. See, for example, Cocco et al. (2005), Heaton and Lucas (2000), and Gomes and Michaelides (2005).

${ }^{48}$ This age pattern of portfolio choice has received mixed support in previous studies. Luo (2006) estimates age profiles of portfolio shares using cross-sectional data from the 2000 wave of the Health and Retirement Study (HRS) and finds evidence of a negative and significant age effect. As Ameriks and Zeldes (2004) argue, however, cross-sectional data make it impossible to disentangle age, time, and cohort effects without strong identifying assumptions; analyzing a panel of TIAA-CREF data, they cannot reject the hypothesis of no age effects. In a study of panel 401(k) data from a single large firm, however, Agnew et al. (2003) find that participants do tend to shift toward safer allocations with age. Controlling for cohort effects, Poterba and Samwick (2001) also find a declining age pattern of risky assets, starting from a peak around age 43.
} 
and children may be comparably important for understanding optimal portfolio decisions. Future work on this topic could extend the framework in several ways in the direction of realism and internal consistency. Along these lines, important improvements would include endogenizing changes in family composition (including fertility, marital matching, and divorce) and providing a richer description of intrahousehold bargaining (e.g., deriving decision weights as the outcome of Nash bargaining, as in Browning, 2000). 


\section{References}

Agnew, Julie, Pierluigi Balduzzi, and Annika Sunden, "Portfolio Choice and Trading in a Large 401(k) Plan," American Economic Review, Mar. 2003, 93 (1), 193-215.

Ameriks, John and Stephen P. Zeldes, "How Do Household Portfolio Shares Vary with Age?," September 2004. Manuscript.

Attanasio, Orazio P. and Martin Browning, "Consumption Over the Life Cycle and Over the Business Cycle," The American Economic Review, 1995, 85 (5), 1118-1137.

_ , James Banks, Costas Meghir, and Guglielmo Weber, "Humps and Bumps in Lifetime Consumption," Journal of Business and Economic Statistics, 1999, 17 (1), 2235.

Bachu, Amara and Martin O'Connell, "Fertility of American Women: June 2000," October 2001. Current Population Current Population Reports, P20-543RV, U.S. Census Bureau, Washington, DC.

Bartfelt, Judi, "Child Support and the Postdivorce Economic Well-Being of Mothers, Fathers, and Children," Demography, 2000, 37 (2).

Becker, Gary S. and Robert J. Barro, "A Reformulation of the Economic Theory of Fertility," The Quarterly Journal of Economics, 1988, 103 (1), 1-25.

Benitez-Silva, Hugo, "The Annuity Puzzle Revisited," June 2003. Michigan Retirement Research Center Working Paper.

Bertaut, C. and M. Haliassos, "Precautionary Portfolio Behavior from a Life-Cycle Perspective," Journal of Economic Dynamics and Control, 1997, 21, 1511-1542.

Bodie, Zvi, Robert C. Merton, and William F. Samuelson, "Labor Flexibility and Porfolio Choice in a Life Cycle Model," Journal of Economic Dynamics and Control, 1992, 16, 427-449.

Browning, Martin, "The Saving Behavior of a Two-Person Household," Scandanavian Journal of Economics, 2000, 102 (2), 235-251.

- and Mette Ejrnæs, "Consumption and Children," 2002. Centre for Applied Microeconometrics Working Paper.

Cagetti, Marco, "Wealth Accumulation Over the Life Cycle and Precautionary Saving," Journal of Business and Economic Statistics, 2003, 21, 339-353.

Campbell, John Y. and Luis M. Viceira, Strategic Asset Allocation, Oxford University Press, 2002.

_, Andrew W. Lo, and A. Craig MacKinlay, The Econometrics of Financial Markets, Princeton University Press, 1997. 
Carroll, Christopher D., "The Buffer-Stock Theory of Saving: Some Macroeconomic Evidence," Brookings Papers on Economic Activity, 1992, 1992 (2), 61-156.

_ , "Buffer-Stock Saving and the Life Cycle/Permanent Income Hypothesis," The Quarterly Journal of Economics, Feb. 1997, 112 (1), 1-55.

_ , "The Method of Endogenous Gridpoints for Solving Dynamic Stochastic Optimization Problems," May 2006. Working Paper.

_ , "Lecture Notes on Solution Methods for Microeconomic Dynamic Stochastic Optimization Problems," August 2007. Lecture Notes.

- and Andrew A. Samwick, "The Nature of Precautionary Wealth," The Journal of Monetary Economics, 1997, 40 (41-71).

Citro, Constance F. and Robert T. Michael, Measuring Poverty: A New Approach, Washington, D.C.: Nat. Acad. Press, 1995.

Cocco, Joao F., "Portfolio Choice in the Presence of Housing," The Review of Financial Studies, 2005, 18 (2), 535-567.

_ , Francisco J. Gomes, and Pascal J. Maenhout, "Consumption and Portfolio Choice over the Life Cycle," The Review of Financial Studies, 2005, 18 (2), 491-533.

Cubeddu, Luis and José-Víctor Ríos-Rull, "Families as Shocks," Journal of the European Economic Association, 2005, April-May (1), 671-682.

Curcuru, Stephanie Curcuru John Heaton Deborah Lucas Stephanie, John Heaton, Deborah Lucas, and Damien Moore, "Heterogeneity and Portfolio Choice: Theory and Evidence," September 2004. Prepared for the Handbook of Financial Econometrics.

De Nardi, Mariacristina, "Wealth Inequality and Intergenerational Links," Review of Economic Studies, 2004, 71, 743-768.

Eisenhauer, Joseph G. and Martin Halek, "Prudence, Risk Aversion, and the Demand for Life Insurance," Applied Economics Letters, 1999, 6 (4), 239-242.

Fischer, Stanley, "A Life Cycle Model of Life Insurance Purchases," International Economic Review, 1973, 14 (1), 132-152.

French, Eric, "The Effects of Health, Wealth, and Wages on Labor Supply and Retirement," Review of Economic Studies, 2005, 72, 395-427.

_ and John Bailey Jones, "The Effects of Health Insurance and Self-Insurance on Retirement Behavior," December 2004. Manuscript.

_ and _, "On the Distribution and Dynamics of Health Care Costs," Journal of Applied Econometrics, 2004, 19, 705-721. 
Gomes, Francisco J. and Alexander Michaelides, "Optimal Life-Cycle Asset Allocation: Understanding the Empirical Evidence," The Journal of Finance, 2005, 60 (2), 869-904.

Gourinchas, Pierre-Olivier and Jonathan A. Parker, "Consumption over the Life Cycle," Econometrica, Jan. 2002, 70 (1), 47-89.

Haliassos, Michael and Alexander Michaelides, "Portfolio Choice and Liquidity Constraints," International Economic Review, 2003, 44 (1), 143-177.

Heaton, John and Deborah Lucas, "Portfolio Choice in the Presence of Background Risk," Economic Journal, Jan. 2000, 110 (460), 1-26.

Hong, Jay H. and José-Víctor Ríos-Rull, "Life Insurance and Household Consumption," June 2006. Working Paper.

Horneff, Wolfram J., Raimond H. Maurer, and Michael Z. Stamos, "Life-Cycle Asset Allocation with Annuity Markets: Is Longevity Insurance a Good Deal?," July 2007. Working Paper.

Hu, Xiaoqing, "Portfolio Choices for Homeowners," Journal of Urban Economics, 2005, $58,114-136$.

Hubbard, R. Glenn, Jonathan Skinner, and Stephen P. Zeldes, "Precautionary Saving and Social Insurance," Journal of Political Economy, Apr. 1995, 103 (2), 360399.

Kimball, Miles S. and Douglas W. Elmendorf, "Taxation of Labor Income and the Demand for Risky Assets," International Economic Review, 2000, 41, 801-832.

Koo, Hyeng Keun, "Consumption and Portfolio Selection with Labor Income: A Continuous Time Approach," Mathematical Finance, 1998, 8 (1), 49.

Laitner, John, "Wealth Inequality and Altruistic Bequests," The American Economic Review, May 2002, 92 (2), 270-273.

Lippman, L., L. Guzman, Keith J. Dombrowski, A. Kinukawa, R. Schwalb, and P. Tice, "Parent Expectations and Planning for College: Statistical Analysis Report (NCES 2008-079)," Technical Report, National Center for Education Statistics, Institute of Education Sciences, U.S. Department of Education, Washington D.C. April 2008.

Love, David A. and Maria G. Perozek, "Should the Old Play it Safe? Portfolio Choice with Uncertain Medical Expenses," 2007. manuscript.

Luo, Jia, "Uncertain Medical Expenses and Portfolio Choice Over the Life Cycle," August 2006. Working Paper.

Matthews, T.J. and Stephanie J. Ventura, "Birth and Fertility Rates by Educational Attainment: United States, 1994," Monthly Vital Statistics Report, April 1997, 45 (10). 
Mehra, Rajnish and Edward C. Prescott, "The Equity Premium: ABCs," in Rajnish Mehra and Edward C. Prescott, eds., Handbook of the Equity Risk Premium, Elsevier, 2008 .

Palumbo, Michael G., "Uncertain Medical Expenses and Precautionary Saving Near the End of the Life Cycle," Review of Economic Studies, Apr. 1999, 66 (2), 395-421.

Pang, Gaobo and Mark Washawsky, "Optimizing the Equity-Bond-Annuity Portfolio in Retirement: The Impact of Uncertain Health Expenses," July 2007. Working Paper.

Poterba, James M. and Andrew A. Samwick, "Household Portfolio Allocation over the Life Cycle," in Seiritsu Ogura, Toshiaki Tachibanaki, and David A. Wise, eds., Aging Issues in the United States and Japan, University of Chicago Press, 2001, pp. 65-104.

Roberts, Paula G., "Child Support Orders: Problems with Enforcement," The Future of Children: Children and Divorce, 1994, 4 (1).

Schmidt, Lucie, "Risk Preferences and the Timing of Marriage and Childbearing," 2008. Forthcoming, Demography.

Scholz, John Karl, Ananth Seshadri, and Surachasi Khitatrakun, "Are Americans Saving "Optimally" For Retirement?," Journal of Political Economy, August 2006, 114, 607-643.

_ and _, "Children and Household Wealth," October 2007. University of Michigan Retirement Research Center WP 2007-158.

Smith, Karen E., Melissa M. Favreault, Caroline Ratcliffe, Barbara Butrica, and Jon Bakija, "Modeling Income in the Near Term 5," 2007. The Urban Institute, Final Report.

Stevenson, Betsey, "The Impact of Divorce Laws on Marriage-Specific Capital," Journal of Labor Economics, 2007, 25 (1), 75-94.

Turley, Ruth N. López and Matthew S. Desmond, "Contributions to College Costs by Married and Divorced Parents," 2006. Manuscript, Institute for Research on Poverty, University of Wisconsin-Madison.

Viceira, Luis M., "Optimal Portfolio Choice for Long-Horizon Investors with Nontradable Labor Income," Journal of Finance, Apr. 2001, 56 (2), 433-470.

Vissing-Jorgensen, Annette, "Towards an Explanation of Household Portfolio Choice Heterogeneity: Nonfinancial Income and Participation Cost Structures," NBER Working Paper No. 8884, 2002.

Wachter, Jessica A. and Motohiro Yogo, "Why Do Household Portfolio Shares Rise in Wealth," July 2007. Working Paper.

Yao, Rui and Harold H. Zhang, "Optimal Consumption and Portfolio Choices with Risky Housing and Borrowing Constraints," Review of Financial Studies, 2005, 18, 197239 . 
Table 1

Income process

\begin{tabular}{|c|c|c|c|c|c|c|}
\hline & \multicolumn{3}{|c|}{ High School } & \multicolumn{3}{|c|}{ College } \\
\hline & Male & Female & Married & Male & Female & Married \\
\hline \multicolumn{7}{|c|}{$\underline{\text { Fitted age polynomials }}$} \\
\hline Constant & -2.0753 & -1.8593 & -1.1018 & -4.0447 & -2.1728 & -1.3505 \\
\hline Age & 0.1625 & 0.1633 & 0.0812 & 0.3352 & 0.2383 & 0.1055 \\
\hline $\mathrm{Age}^{2} / 100$ & -0.2902 & -0.3026 & -0.0889 & -0.6589 & -0.3960 & -0.0801 \\
\hline $\mathrm{Age}^{3} / 10000$ & 0.1634 & 0.1803 & 0.0046 & 0.4167 & 0.2056 & -0.0282 \\
\hline Replacement rate & 0.8411 & 0.8370 & 0.8487 & 0.8274 & 0.7357 & 0.7421 \\
\hline \multicolumn{7}{|l|}{$\underline{\text { Coefficient estimates }}$} \\
\hline Children age $0-1$ & $\begin{array}{c}0.0023 \\
(0.1317)\end{array}$ & $\begin{array}{c}-0.0294 \\
(0.0265)\end{array}$ & $\begin{array}{c}-0.0231 \\
(0.0049)\end{array}$ & $\begin{array}{c}0.1725 \\
(0.1673)\end{array}$ & $\begin{array}{l}-0.1560 \\
(0.0768)\end{array}$ & $\begin{array}{c}-0.0399 \\
(0.0078)\end{array}$ \\
\hline Children age $2-4$ & $\begin{array}{l}-0.0656 \\
(0.0880)\end{array}$ & $\begin{array}{l}-0.0038 \\
(0.0221)\end{array}$ & $\begin{array}{l}-0.0226 \\
(0.0045)\end{array}$ & $\begin{array}{c}-0.0871 \\
(0.1388)\end{array}$ & $\begin{array}{l}-0.0878 \\
(0.0574)\end{array}$ & $\begin{array}{c}-0.0204 \\
(0.0074)\end{array}$ \\
\hline Children age $5-7$ & $\begin{array}{c}0.0272 \\
(0.0614)\end{array}$ & $\begin{array}{l}-0.0017 \\
(0.0197)\end{array}$ & $\begin{array}{l}-0.0020 \\
(0.0045)\end{array}$ & $\begin{array}{c}0.0905 \\
(0.1236)\end{array}$ & $\begin{array}{c}-0.0744 \\
(0.0481)\end{array}$ & $\begin{array}{c}-0.0148 \\
(0.0075)\end{array}$ \\
\hline Children age $8-10$ & $\begin{array}{c}-0.0045 \\
(0.0529)\end{array}$ & $\begin{array}{c}0.0048 \\
(0.0202)\end{array}$ & $\begin{array}{c}0.0088 \\
(0.0046)\end{array}$ & $\begin{array}{c}-0.0376 \\
(0.1414)\end{array}$ & $\begin{array}{c}-0.0688 \\
(0.0466)\end{array}$ & $\begin{array}{c}-0.0010 \\
(0.0078)\end{array}$ \\
\hline Children age $11-12$ & $\begin{array}{c}0.0562 \\
(0.0574)\end{array}$ & $\begin{array}{c}0.0371 \\
(0.0210)\end{array}$ & $\begin{array}{c}0.0294 \\
(0.0051)\end{array}$ & $\begin{array}{c}0.1415 \\
(0.1186)\end{array}$ & $\begin{array}{c}-0.0262 \\
(0.0463)\end{array}$ & $\begin{array}{c}0.0196 \\
(0.0087)\end{array}$ \\
\hline Children age $13-15$ & $\begin{array}{c}0.0430 \\
(0.0489)\end{array}$ & $\begin{array}{c}0.0795 \\
(0.0200)\end{array}$ & $\begin{array}{c}0.0200 \\
(0.0052)\end{array}$ & $\begin{array}{c}0.0062 \\
(0.1083)\end{array}$ & $\begin{array}{c}0.0648 \\
(0.0445)\end{array}$ & $\begin{array}{c}0.0304 \\
(0.0090)\end{array}$ \\
\hline Children age $16-18$ & $\begin{array}{c}0.0289 \\
(0.0557)\end{array}$ & $\begin{array}{c}0.1501 \\
(0.0232)\end{array}$ & $\begin{array}{c}0.0454 \\
(0.0060)\end{array}$ & $\begin{array}{c}0.0455 \\
(0.0847)\end{array}$ & $\begin{array}{c}0.1331 \\
(0.0475)\end{array}$ & $\begin{array}{c}0.0414 \\
(0.0107)\end{array}$ \\
\hline Constant & $\begin{array}{c}9.4719 \\
(0.0546)\end{array}$ & $\begin{array}{c}9.1591 \\
(0.0579)\end{array}$ & $\begin{array}{c}9.9748 \\
(0.0212)\end{array}$ & $\begin{array}{c}9.0156 \\
(0.2549)\end{array}$ & $\begin{array}{c}7.9791 \\
(0.2119)\end{array}$ & $\begin{array}{c}9.6519 \\
(0.1051)\end{array}$ \\
\hline $\mathrm{N}$ & 4339 & 5780 & 48127 & 1911 & 1980 & 20466 \\
\hline R-squared & 0.100 & 0.129 & 0.120 & 0.252 & 0.262 & 0.219 \\
\hline Variance decompos & & & & & & \\
\hline Permanent $\left(\sigma_{\zeta}^{2}\right)$ & $\begin{array}{c}0.0099 \\
(0.0025)\end{array}$ & $\begin{array}{c}0.0119 \\
(0.0015)\end{array}$ & $\begin{array}{c}0.0092 \\
(0.0007)\end{array}$ & $\begin{array}{c}0.0094 \\
(0.0021)\end{array}$ & $\begin{array}{c}0.0169 \\
(0.0012)\end{array}$ & $\begin{array}{c}0.0130 \\
(0.0007)\end{array}$ \\
\hline Transitory $\left(\sigma_{\epsilon}^{2}\right)$ & $\begin{array}{c}0.0894 \\
(0.0254)\end{array}$ & $\begin{array}{c}0.0851 \\
(0.0153)\end{array}$ & $\begin{array}{c}0.0635 \\
(0.0068)\end{array}$ & $\begin{array}{c}0.0786 \\
(0.0218)\end{array}$ & $\begin{array}{c}0.0418 \\
(0.0124)\end{array}$ & $\begin{array}{c}0.0588 \\
(0.0070)\end{array}$ \\
\hline
\end{tabular}

This table presents the fitted age polynomials, coefficient estimates, and variance decomposition from separate fixed-effects regressions (by education, gender, and marital status subsamples) of the natural logarithm of income on a full set of age dummies and the number of children of different ages living in the household. The data are taken from the 1980-2003 waves of the PSID. Income is the sum of household labor income and public transfers less income and payroll taxes. We restrict the sample to respondents aged 20-65 with no additional adults apart from a spouse living in the household, and we exclude observations with incomes less than $\$ 3,000$ or greater than $\$ 3,000,000$. To estimate the replacement rates, we first run fixed-effects regressions of log income on age dummies for each education, gender, and marital status subsample for respondents aged 55 to 90 in the 1992-2006 waves of the HRS. We then define the replacement rate as the average income implied by the age dummy coefficient estimates for ages 55-62 divided by the average income for ages 67-80. The estimation procedure for the error structure follows Carroll and Samwick (1997). 
Table 2

Housing costs

\begin{tabular}{|c|c|c|c|c|c|c|}
\hline & \multicolumn{3}{|c|}{ High School } & \multicolumn{3}{|c|}{ College } \\
\hline & Male & Female & Married & Male & Female & Married \\
\hline \multirow[t]{2}{*}{ Age } & -0.0218 & -0.0049 & -0.0006 & -0.0218 & -0.0049 & -0.0006 \\
\hline & $(0.0103)$ & $(0.0087)$ & $(0.0035)$ & $(0.0103)$ & $(0.0087)$ & $(0.0035)$ \\
\hline \multirow[t]{2}{*}{$\mathrm{Age}^{2} / 100$} & 0.0590 & 0.0114 & -0.0015 & 0.0590 & 0.0114 & -0.0015 \\
\hline & $(0.0266)$ & $(0.0213)$ & $(0.0082)$ & $(0.0266)$ & $(0.0213)$ & $(0.0082)$ \\
\hline \multirow{2}{*}{$\operatorname{Age}^{3} / 10000$} & -0.0520 & -0.0100 & 0.0011 & -0.0520 & -0.0100 & 0.0011 \\
\hline & $(0.0219)$ & $(0.0166)$ & $(0.0061)$ & $(0.0219)$ & $(0.0166)$ & $(0.0061)$ \\
\hline \multirow{2}{*}{ Adults in $\mathrm{HH}$} & 0.0061 & -0.0267 & -0.0107 & 0.0061 & -0.0267 & -0.0107 \\
\hline & $(0.0064)$ & $(0.0046)$ & $(0.0017)$ & $(0.0064)$ & $(0.0046)$ & $(0.0017)$ \\
\hline \multirow{2}{*}{1 child } & 0.0228 & 0.0170 & 0.0052 & 0.0228 & 0.0170 & 0.0052 \\
\hline & $(0.0123)$ & $(0.0085)$ & $(0.0026)$ & $(0.0123)$ & $(0.0085)$ & $(0.0026)$ \\
\hline \multirow[t]{2}{*}{2 children } & -0.0011 & 0.0156 & 0.0052 & -0.0011 & 0.0156 & 0.0052 \\
\hline & $(0.0168)$ & $(0.0109)$ & $(0.0030)$ & $(0.0168)$ & $(0.0109)$ & $(0.0030)$ \\
\hline \multirow[t]{2}{*}{$3+$ children } & 0.0085 & 0.0367 & 0.0010 & 0.0085 & 0.0367 & 0.0010 \\
\hline & $(0.0274)$ & $(0.0159)$ & $(0.0040)$ & $(0.0274)$ & $(0.0159)$ & $(0.0040)$ \\
\hline \multirow[t]{2}{*}{ State UE Rate (pct) } & -0.0007 & 0.0017 & 0.0007 & -0.0007 & 0.0017 & 0.0007 \\
\hline & $(0.0020)$ & $(0.0016)$ & $(0.0005)$ & $(0.0020)$ & $(0.0016)$ & $(0.0005)$ \\
\hline \multirow[t]{2}{*}{ Constant } & 0.4549 & 0.3206 & 0.2057 & 0.4549 & 0.3206 & 0.2057 \\
\hline & $(0.1285)$ & $(0.1112)$ & $(0.0469)$ & $(0.1285)$ & $(0.1112)$ & $(0.0469)$ \\
\hline $\mathrm{N}$ & 4395 & 6130 & 16892 & 4395 & 6130 & 16892 \\
\hline R-squared & 0.004 & 0.012 & 0.014 & 0.004 & 0.012 & 0.014 \\
\hline
\end{tabular}

This table reports the coefficient estimates from separate fixed-effects regressions (by education, gender, and marital status subsamples) of the ratio of annual housing costs (mortgage payments plus rent) to income on a cubic age polynomial, number of children of different ages living in the household, number of adults in the household, and state unemployment rates.

Table 3

Example of how marital status affects household resources

\begin{tabular}{lcccccc}
\hline \hline & \multicolumn{2}{c}{$\begin{array}{c}\text { Divorced } \rightarrow \\
\text { married }\end{array}$} & \multicolumn{2}{c}{$\begin{array}{c}\text { Married } \rightarrow \\
\text { divorced }\end{array}$} & \multicolumn{2}{c}{$\begin{array}{c}\text { Married } \rightarrow \\
\text { widowed }\end{array}$} \\
& Men & Women & Men & Women & Men & Women \\
\hline$\Delta$ permanent income $(\$ 1000 \mathrm{~s})$ & +19.13 & +34.80 & -20.78 & -28.44 & -20.78 & -28.44 \\
$\Delta$ net child support receipts $(\$ 1000 \mathrm{~s})$ & +4.25 & -4.25 & -4.25 & +4.25 & - & - \\
$\Delta$ wealth $(\$ 1000 \mathrm{~s})$ & +64.00 & +77.50 & -90.00 & -90.00 & +100.00 & 0.00 \\
$\Delta$ equiv. scales & +1.00 & +0.55 & -1.00 & -0.55 & -0.55 & -0.55 \\
\hline
\end{tabular}

This table reports the changes in household resources due to a change in marital status for 40-year-old high school graduates with one 13-year-old child. The change in permanent income is a combination of the marital status effect as well as the trend growth rate in the income profiles. The change in wealth reflects only the change due to marriage, divorce, or widowhood, holding other saving constant. Before the change in marital status, both single men and women are assumed to have $\$ 25,000$ in permanent income, while married couples are assumed to have $\$ 50,000$ in permanent income, $\$ 200,000$ in wealth, and a life insurance policy for the husband with a death benefit of $\$ 100,000$. Note that child support is $17 \%$ of income for a single child; divorce triggers a $55 \%$ reduction in assets (the 50/50 split plus an additional $5 \%$ in court fees); and the formula for the equivalence scales is $\left(A+K^{0.7}\right)^{0.7}$, where $A$ and $K$ denote the number of adults and children living in the household. 
Table 4

Portfolio shares by age in the PSID and the HRS

\begin{tabular}{|c|c|c|c|c|c|c|}
\hline \multirow[t]{2}{*}{ Ages } & \multicolumn{2}{|c|}{ Married } & \multicolumn{2}{|c|}{ Single men } & \multicolumn{2}{|c|}{ Single women } \\
\hline & Conditional & Unconditional & Conditional & Unconditional & Conditional & Unconditional \\
\hline $20-30$ & 0.44 & 0.15 & 0.49 & 0.11 & 0.44 & 0.07 \\
\hline $30-40$ & 0.43 & 0.19 & 0.46 & 0.15 & 0.45 & 0.10 \\
\hline $40-50$ & 0.44 & 0.18 & 0.46 & 0.14 & 0.50 & 0.15 \\
\hline $50-60$ & 0.58 & 0.23 & 0.60 & 0.16 & 0.60 & 0.14 \\
\hline $60-70$ & 0.57 & 0.23 & 0.60 & 0.17 & 0.60 & 0.15 \\
\hline $70-80$ & 0.55 & 0.23 & 0.56 & 0.16 & 0.55 & 0.14 \\
\hline
\end{tabular}

This table reports the average stock shares for different age brackets and marital status groups conditional and unconditional on participation in the stockmarket (defined as having a positive share). The stock share is the ratio of the market value of stocks (directly-held, mutual funds, and investment trusts, excluding IRAs and Keoghs) divided by net financial wealth. For ages 20-50, we compute mean allocations using the 1999-2005 wealth supplements in the PSID (excluding the SEO oversample). For ages 50-80, we use the 1992-2006 waves of the HRS. The means were calculated using the sampling weights in the HRS and the PSID. 
Table 5

Average simulated stock allocations by marital status and children

\begin{tabular}{|c|c|c|c|c|c|c|c|c|c|c|}
\hline \multicolumn{11}{|c|}{ High School } \\
\hline \multirow[t]{2}{*}{ Age } & \multicolumn{2}{|c|}{ All } & \multicolumn{2}{|c|}{ Married } & \multicolumn{2}{|c|}{ Never Married } & \multicolumn{2}{|c|}{ Divorced } & \multicolumn{2}{|c|}{ Widowed } \\
\hline & Kids & No Kids & Kids & No Kids & Kids & No Kids & Kids & No Kids & Kids & No Kids \\
\hline \multicolumn{11}{|l|}{ Men } \\
\hline $30-40$ & 96.7 & 95.3 & 96.8 & 92.9 & 94.6 & 98.8 & 99.4 & 99.0 & 93.5 & 92.6 \\
\hline $45-55$ & 79.6 & 65.5 & 77.1 & 60.0 & 86.9 & 79.0 & 88.6 & 80.3 & 77.2 & 61.7 \\
\hline $55-65$ & 54.8 & 48.7 & 52.0 & 44.2 & 66.6 & 62.5 & 64.7 & 63.5 & 53.9 & 46.5 \\
\hline $75-85$ & 37.5 & 42.4 & 38.2 & 38.7 & 39.9 & 59.9 & 36.8 & 58.5 & 34.8 & 38.8 \\
\hline \multicolumn{11}{|l|}{ Women } \\
\hline $30-40$ & 95.9 & 92.3 & 95.9 & 92.1 & 98.9 & 96.5 & 95.4 & 89.4 & 67.6 & 61.7 \\
\hline $45-55$ & 76.5 & 59.8 & 76.5 & 59.5 & 83.3 & 67.3 & 77.9 & 59.7 & 59.3 & 42.9 \\
\hline $55-65$ & 52.7 & 45.1 & 51.8 & 44.0 & 61.1 & 53.2 & 57.1 & 48.3 & 43.8 & 36.2 \\
\hline $75-85$ & 37.6 & 40.2 & 38.1 & 38.6 & 43.5 & 52.1 & 42.0 & 48.1 & 33.7 & 34.3 \\
\hline \multicolumn{11}{|c|}{ College } \\
\hline \multirow[t]{2}{*}{ Age } & \multicolumn{2}{|c|}{ All } & \multicolumn{2}{|c|}{ Married } & \multicolumn{2}{|c|}{ Never Married } & \multicolumn{2}{|c|}{ Divorced } & \multicolumn{2}{|c|}{ Widowed } \\
\hline & Kids & No Kids & Kids & No Kids & Kids & No Kids & Kids & No Kids & Kids & No Kids \\
\hline \multicolumn{11}{|l|}{ Men } \\
\hline $30-40$ & 91.6 & 96.4 & 90.5 & 88.1 & 99.3 & 99.8 & 99.0 & 99.3 & 89.8 & 92.0 \\
\hline $45-55$ & 73.8 & 67.6 & 71.9 & 56.8 & 85.5 & 79.8 & 83.4 & 76.4 & 71.2 & 56.3 \\
\hline $55-65$ & 47.3 & 45.1 & 44.9 & 39.0 & 60.5 & 54.9 & 57.8 & 53.6 & 48.0 & 41.1 \\
\hline $75-85$ & 32.6 & 35.9 & 32.7 & 33.0 & 38.1 & 43.5 & 33.5 & 42.8 & 30.7 & 32.9 \\
\hline \multicolumn{11}{|l|}{ Women } \\
\hline $30-40$ & 87.2 & 91.0 & 87.8 & 85.5 & 98.8 & 97.5 & 77.1 & 68.9 & 66.1 & 64.1 \\
\hline $45-55$ & 67.0 & 54.6 & 70.4 & 55.6 & 70.0 & 57.2 & 55.2 & 43.3 & 56.3 & 42.3 \\
\hline $55-65$ & 43.1 & 38.6 & 44.4 & 38.5 & 44.1 & 40.3 & 40.4 & 36.0 & 39.1 & 33.5 \\
\hline $75-85$ & 31.9 & 33.2 & 32.3 & 32.7 & 35.2 & 35.5 & 33.9 & 34.4 & 29.8 & 29.6 \\
\hline
\end{tabular}

This table presents the average simulated percentage shares in the risky asset by age, gender, and marital status. The columns titled "Kids" and "No Kids" report results for households with at least one child and no children, respectively. Averages are taken over 50,000 independent simulations of returns, income, children, marital status, and mortality for the baseline specification of the model. The baseline model is solved for a coefficient of relative risk aversion $\rho=6$, a correlation between stocks and permanent income $\operatorname{corr}_{r, y}=0.15$, and the pair of the discount factor $\beta$ and the bequest parameter $b$ that minimizes the sum of squared deviations between the simulated and empirical median cash-on-hand to income ratios for 5 -year age brackets between 20 and 95 . For high school graduates, $\beta=0.9215$ and $b=3.25$, and for college graduates, $\beta=0.9050$ and $b=4.00$. See text for details. 
Table 6

Average simulated levels of cash on hand (in thousands) by marital status and children

\begin{tabular}{|c|c|c|c|c|c|c|c|c|c|c|}
\hline \multicolumn{11}{|c|}{ High School } \\
\hline \multirow[t]{2}{*}{ Age } & \multicolumn{2}{|c|}{ All } & \multicolumn{2}{|c|}{ Married } & \multicolumn{2}{|c|}{ Never Married } & \multicolumn{2}{|c|}{ Divorced } & \multicolumn{2}{|c|}{ Widowed } \\
\hline & Kids & No Kids & Kids & No Kids & Kids & No Kids & Kids & No Kids & Kids & No Kids \\
\hline \multicolumn{11}{|l|}{ Men } \\
\hline $30-40$ & 100.3 & 126.5 & 122.6 & 160.0 & 46.7 & 66.6 & 51.9 & 74.5 & 93.8 & 125.2 \\
\hline $45-55$ & 192.5 & 287.9 & 222.3 & 337.6 & 93.8 & 143.8 & 93.9 & 155.2 & 162.0 & 278.7 \\
\hline $55-65$ & 283.1 & 361.9 & 324.2 & 415.9 & 138.3 & 178.0 & 137.7 & 185.9 & 248.7 & 348.0 \\
\hline $75-85$ & 285.1 & 279.7 & 316.7 & 320.0 & 159.2 & 146.7 & 151.6 & 130.5 & 279.2 & 293.7 \\
\hline \multicolumn{11}{|l|}{ Women } \\
\hline $30-40$ & 106.5 & 128.7 & 129.3 & 168.6 & 37.6 & 48.4 & 51.3 & 65.4 & 114.7 & 150.2 \\
\hline $45-55$ & 186.8 & 276.8 & 225.8 & 342.8 & 74.4 & 113.4 & 86.2 & 130.4 & 170.0 & 269.8 \\
\hline $55-65$ & 264.9 & 335.3 & 328.3 & 421.2 & 112.5 & 143.1 & 124.2 & 159.5 & 244.3 & 337.4 \\
\hline $75-85$ & 244.9 & 241.5 & 319.8 & 323.1 & 125.1 & 118.5 & 135.1 & 127.1 & 259.0 & 259.3 \\
\hline \multicolumn{11}{|c|}{ College } \\
\hline \multirow[t]{2}{*}{ Age } & \multicolumn{2}{|c|}{ All } & \multicolumn{2}{|c|}{ Married } & \multicolumn{2}{|c|}{ Never Married } & \multicolumn{2}{|c|}{ Divorced } & \multicolumn{2}{|c|}{ Widowed } \\
\hline & Kids & No Kids & Kids & No Kids & Kids & No Kids & Kids & No Kids & Kids & No Kids \\
\hline \multicolumn{11}{|l|}{ Men } \\
\hline $30-40$ & 168.6 & 124.8 & 190.5 & 239.0 & 50.3 & 64.8 & 72.3 & 87.0 & 147.6 & 170.0 \\
\hline $45-55$ & 332.5 & 387.2 & 376.0 & 547.1 & 125.4 & 184.0 & 144.4 & 216.4 & 255.9 & 409.4 \\
\hline $55-65$ & 518.1 & 553.1 & 587.6 & 735.6 & 191.0 & 246.3 & 218.7 & 280.4 & 415.0 & 573.1 \\
\hline $75-85$ & 565.7 & 493.8 & 620.6 & 595.7 & 253.5 & 246.4 & 287.9 & 253.9 & 564.5 & 566.2 \\
\hline \multicolumn{11}{|l|}{ Women } \\
\hline $30-40$ & 177.4 & 127.5 & 206.6 & 259.2 & 50.3 & 64.8 & 87.4 & 108.5 & 152.1 & 173.4 \\
\hline $45-55$ & 331.8 & 376.0 & 392.3 & 570.7 & 153.5 & 216.3 & 185.8 & 263.5 & 274.3 & 429.1 \\
\hline $55-65$ & 500.6 & 516.8 & 608.1 & 761.2 & 241.7 & 303.4 & 283.0 & 343.7 & 446.4 & 601.1 \\
\hline $75-85$ & 507.1 & 422.5 & 638.6 & 613.0 & 265.5 & 274.7 & 319.0 & 287.9 & 538.2 & 525.9 \\
\hline
\end{tabular}

This table presents the average simulated levels of cash on hand by age, gender, and marital status. The columns titled "Kids" and "No Kids" report results for households with at least one child and no children, respectively. Averages are taken over 50,000 independent simulations of returns, income, children, marital status, and mortality for the baseline specification of the model. The baseline model is solved for a coefficient of relative risk aversion $\rho=6$, a correlation between stocks and permanent income $\operatorname{corr}_{r, y}=0.15$, and the pair of the discount factor $\beta$ and the bequest parameter $b$ that minimizes the sum of squared deviations between the simulated and empirical median cash-on-hand to income ratios for 5-year age brackets between 20 and 95 . For high school graduates, $\beta=0.9215$ and $b=3.25$, and for college graduates, $\beta=0.9050$ and $b=4.00$. See text for details. 
Table 7

Marital transitions and simulated changes in stock allocations

\begin{tabular}{|c|c|c|c|c|c|c|c|c|c|c|}
\hline \multicolumn{11}{|c|}{ High School } \\
\hline \multirow[t]{2}{*}{ Age } & \multicolumn{2}{|c|}{$\begin{array}{l}\text { First } \\
\text { marriage }\end{array}$} & \multicolumn{2}{|c|}{$\begin{array}{l}\text { Married } \rightarrow \\
\text { divorced }\end{array}$} & \multicolumn{2}{|c|}{$\begin{array}{c}\text { Married } \rightarrow \\
\text { widowed }\end{array}$} & \multicolumn{2}{|c|}{$\begin{array}{l}\text { Divorced } \rightarrow \\
\text { married }\end{array}$} & \multicolumn{2}{|c|}{$\begin{array}{l}\text { Widowed } \rightarrow \\
\text { married }\end{array}$} \\
\hline & Kids & No Kids & Kids & No Kids & Kids & No Kids & Kids & No Kids & Kids & No Kids \\
\hline \multicolumn{11}{|l|}{ Men } \\
\hline $30-40$ & 4.6 & -0.4 & 2.3 & 4.4 & -5.4 & -3.5 & 0.2 & 0.3 & 1.1 & -2.3 \\
\hline $45-55$ & -5.2 & -9.5 & 9.4 & 18.8 & -8.1 & -4.9 & -6.1 & -11.6 & -5.4 & -6.3 \\
\hline $55-65$ & -10.1 & -11.1 & 9.2 & 15.8 & -5.5 & -2.0 & -9.4 & -13.6 & -6.1 & -6.5 \\
\hline $75-85$ & -0.0 & -21.2 & -0.9 & 11.9 & -4.2 & -2.0 & 2.4 & -17.9 & -0.4 & -4.7 \\
\hline \multicolumn{11}{|l|}{ Women } \\
\hline $30-40$ & 0.8 & 2.6 & -2.7 & -5.2 & -37.6 & -37.6 & 3.7 & 8.3 & 10.5 & 9.7 \\
\hline $45-55$ & -3.0 & 3.1 & -3.9 & -3.8 & -28.2 & -20.9 & 0.9 & 7.4 & 1.8 & 1.6 \\
\hline $55-65$ & -6.2 & -3.4 & -0.8 & 0.1 & -15.7 & -11.1 & -3.3 & 0.4 & -0.1 & 0.1 \\
\hline $75-85$ & -6.8 & -9.1 & 2.5 & 4.8 & -6.6 & -6.8 & -4.8 & -9.3 & -2.4 & -3.2 \\
\hline \multicolumn{11}{|c|}{ College } \\
\hline \multirow[t]{2}{*}{ Age } & \multicolumn{2}{|c|}{$\begin{array}{c}\text { First } \\
\text { marriage }\end{array}$} & \multicolumn{2}{|c|}{$\underset{\text { divorced }}{\text { Married } \rightarrow}$} & \multicolumn{2}{|c|}{$\begin{array}{l}\text { Married } \rightarrow \\
\text { widowed }\end{array}$} & \multicolumn{2}{|c|}{$\begin{array}{c}\text { Divorced } \rightarrow \\
\text { married }\end{array}$} & \multicolumn{2}{|c|}{$\begin{array}{l}\text { Widowed } \rightarrow \\
\text { married }\end{array}$} \\
\hline & Kids & No Kids & Kids & No Kids & Kids & No Kids & Kids & No Kids & Kids & No Kids \\
\hline \multicolumn{11}{|l|}{ Men } \\
\hline $30-40$ & -0.8 & -1.6 & 8.2 & 7.5 & -4.3 & 0.1 & -3.7 & -2.8 & -10.8 & -12.3 \\
\hline $45-55$ & -12.0 & -13.1 & 8.7 & 16.7 & -10.7 & -7.1 & -9.2 & -12.7 & -6.3 & -3.3 \\
\hline $55-65$ & -12.7 & -9.3 & 8.7 & 11.2 & -4.5 & -2.4 & -9.9 & -9.8 & -5.6 & -3.2 \\
\hline $75-85$ & -3.1 & -7.0 & 1.0 & 7.1 & -2.6 & -1.6 & 0.7 & -7.2 & -0.2 & -2.3 \\
\hline \multicolumn{11}{|l|}{ Women } \\
\hline $30-40$ & -6.4 & -6.3 & -12.5 & -16.4 & -37.0 & -31.9 & 4.7 & 10.8 & -0.3 & -5.2 \\
\hline $45-55$ & -8.6 & 0.2 & -9.9 & -8.7 & -23.9 & -18.4 & 7.1 & 10.7 & -0.7 & -4.5 \\
\hline $55-65$ & -1.3 & 0.4 & -2.6 & -1.2 & -10.6 & -7.9 & 3.2 & 4.0 & -1.4 & -0.7 \\
\hline $75-85$ & -4.2 & -2.9 & 2.2 & 2.8 & -4.0 & -4.2 & -2.2 & -2.2 & -1.7 & -2.3 \\
\hline
\end{tabular}

This table presents the simulated detrended percentage point changes in the portfolio allocation in stocks when there is a transition to a new marital status. The change in the stock share is $\Delta \varsigma-\Delta \bar{\zeta}$, where $\Delta \bar{\zeta}$ denotes the average change for each age bracket if there is no change in marital status, and $\Delta \varsigma$ denotes the average change for each age when marital status changes. The columns titled "Kids" and "No Kids" report results for households with at least one child and no children, respectively. Averages are taken over 50,000 independent simulations of returns, income, children, marital status, and mortality for the baseline specification of the model. The baseline model is solved for a coefficient of relative risk aversion $\rho=6$, a correlation between stocks and permanent income $\operatorname{corr}_{r, y}=0.15$, and the pair of the discount factor $\beta$ and the bequest parameter $b$ that minimizes the sum of squared deviations between the simulated and empirical median cash-on-hand to income ratios for 5-year age brackets between 20 and 95 . For high school graduates, $\beta=0.9215$ and $b=3.25$, and for college graduates, $\beta=0.9050$ and $b=4.00$. See text for details. 
Table 8

Simulated changes in stock allocation for alternative specifications

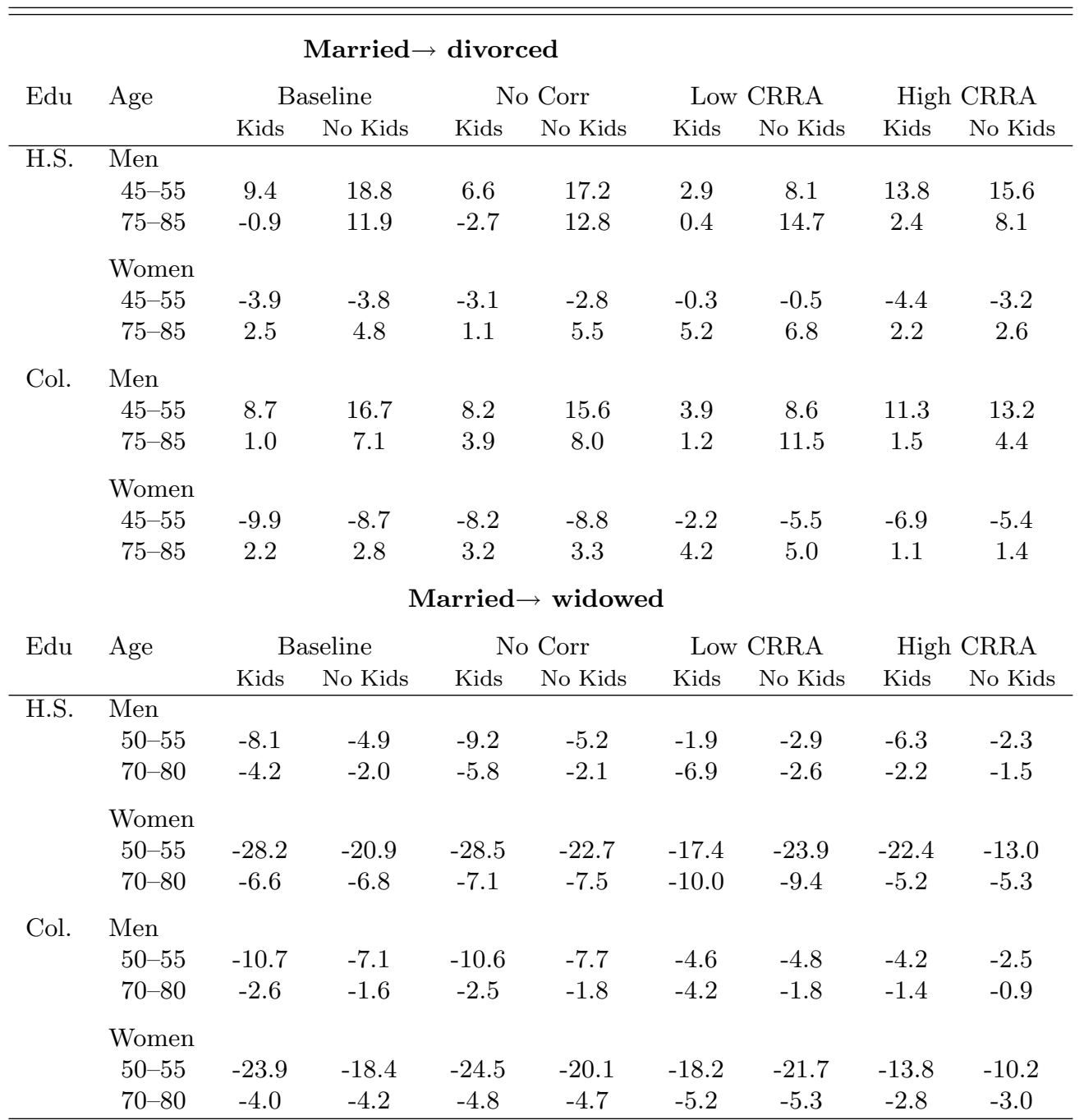

This table displays the simulated detrended percentage point changes in the portfolio allocation in stocks when there is a transition to either divorce or widowhood. "Baseline" is solved for a coefficient of relative risk aversion $\rho=6$ and a correlation between asset returns and permanent income of 0.15. "No Corr" sets the correlation between asset returns and permanent income to 0 . "Low CRRA" alters the baseline specification by setting $\rho=4$. "Low CRRA" alters the baseline specification by setting $\rho=8$. For each specification, the discount factor $\beta$ and the bequest parameter $b$ are chosen to minimize the squared deviations between the simulated and empirical median net wealth levels for 5-year age brackets between 20 and 95 . The estimated values for $\beta$ and $b$ are reported in the main text. The change in the stock share is $\Delta \varsigma-\Delta \bar{\zeta}$, where $\Delta \bar{\varsigma}$ denotes the average change for each age bracket if there is no change in marital status, and $\Delta \varsigma$ denotes the average change for each age when marital status changes. The columns titled "Kids" report results for households with at least one child. The columns titled "No Kids" report results for households with no children. See text for details. 
Table 9

RE tobit regressions of stock share on marital transitions, HRS

\begin{tabular}{lcccccc}
\hline \hline & \multicolumn{2}{c}{ Divorced } & \multicolumn{2}{c}{ Widowed } & \multicolumn{2}{c}{ Never-married } \\
& Male & Female & Male & Female & Male & Female \\
\hline Marital $\times$ Dropout & -0.046 & -0.035 & $-0.064^{* * *}$ & $-0.096^{* * *}$ & $-0.084^{*}$ & $-0.111^{* *}$ \\
& $(0.029)$ & $(0.032)$ & $(0.015)$ & $(0.008)$ & $(0.038)$ & $(0.037)$ \\
Marital $\times$ High School & $-0.044^{* *}$ & $-0.040^{* *}$ & $-0.052^{* * *}$ & $-0.028^{* * *}$ & $-0.077^{* *}$ & -0.018 \\
& $(0.015)$ & $(0.013)$ & $(0.011)$ & $(0.006)$ & $(0.025)$ & $(0.025)$ \\
Marital $\times$ College & -0.028 & -0.022 & 0.016 & -0.010 & -0.035 & 0.007 \\
Nonwhite & $(0.016)$ & $(0.014)$ & $(0.014)$ & $(0.008)$ & $(0.026)$ & $(0.027)$ \\
& $-0.088^{* * *}$ & $-0.091^{* * *}$ & $-0.091^{* * *}$ & $-0.087^{* * *}$ & $-0.092^{* * *}$ & $-0.091^{* * *}$ \\
Health & $(0.009)$ & $(0.009)$ & $(0.009)$ & $(0.008)$ & $(0.009)$ & $(0.010)$ \\
& $-0.021^{* * *}$ & $-0.023^{* * *}$ & $-0.023^{* * *}$ & $-0.020^{* * *}$ & $-0.021^{* * *}$ & $-0.023^{* * *}$ \\
Wealth-income ratio & $(0.004)$ & $(0.004)$ & $(0.004)$ & $(0.003)$ & $(0.004)$ & $(0.004)$ \\
& $0.004^{* * *}$ & $0.004^{* * *}$ & $0.004^{* * *}$ & $0.004^{* * *}$ & $0.004^{* * *}$ & $0.004^{* * *}$ \\
Age & $(0.000)$ & $(0.000)$ & $(0.000)$ & $(0.000)$ & $(0.000)$ & $(0.000)$ \\
Age sq./100 & -0.003 & $-0.011^{* *}$ & -0.005 & $-0.013^{* * *}$ & -0.003 & $-0.010^{*}$ \\
High School & $(0.003)$ & $(0.004)$ & $(0.003)$ & $(0.003)$ & $(0.003)$ & $(0.004)$ \\
& 0.001 & $0.007^{*}$ & 0.003 & $0.008^{* * *}$ & 0.001 & $0.006^{*}$ \\
College & $(0.002)$ & $(0.003)$ & $(0.002)$ & $(0.002)$ & $(0.002)$ & $(0.003)$ \\
& 0.011 & $0.021^{* *}$ & 0.011 & $0.018^{* *}$ & $0.013^{*}$ & $0.023^{* * *}$ \\
Year Dummies & $(0.006)$ & $(0.007)$ & $(0.006)$ & $(0.006)$ & $(0.006)$ & $(0.007)$ \\
N & $0.125^{* * *}$ & $0.100^{* * *}$ & $0.122^{* * *}$ & $0.093^{* * *}$ & $0.126^{* * *}$ & $0.103^{* * *}$ \\
\hline & $(0.006)$ & $(0.007)$ & $(0.006)$ & $(0.006)$ & $(0.006)$ & $(0.007)$ \\
& yes & yes & yes & yes & yes & yes \\
& 26210 & 23696 & 27084 & 30653 & 25532 & 22518 \\
\hline
\end{tabular}

This table reports marginal effects from separate random effects tobit regressions of the stock share on marital status and other household characteristics. Separate regressions were estimated for men and women in each of three marital status categories: "Divorced" includes respondents who are either divorced or married; "Widowed" includes those who are widowed or married; and "Never-married" includes those who are either never-married or married. The interpretation of the indicator variable "Marital x Edu" depends on the subsample, such that "Marital" corresponds to "Divorced," "Widowed," or "Never-married," depending on the column of interest. "Health" is an indicator for whether self-reported health takes a value of $3-5$, on a scale of $1-5$, with higher values indicating worse health. "Wealth-income ratio" is the average ratio of net wealth to income. Data taken from the 1992-2006 waves of the HRS and restricted to respondents aged 60 to 90 . The stock share is the net value of stocks (directly-held, mutual funds, and investment trusts) divided by net financial wealth. Asterisks denote the following levels of statistical significance: ${ }^{*} p<0.05,{ }^{* *} p<0.01,{ }^{* * *} p<0.001$. See text for details. 
Table 10

RE tobit regressions of stock share on marital transitions, PSID

\begin{tabular}{lcccc}
\hline \hline & \multicolumn{2}{c}{ Divorced } & \multicolumn{2}{c}{ Never-married } \\
& Male & Female & Male & Female \\
\hline Marital $\times$ Dropout & -0.044 & -0.051 & -0.017 & $-0.135^{* * *}$ \\
& $(0.029)$ & $(0.047)$ & $(0.041)$ & $(0.039)$ \\
Marital $\times$ High School & 0.024 & $-0.063^{* * *}$ & $0.056^{*}$ & 0.001 \\
& $(0.014)$ & $(0.014)$ & $(0.024)$ & $(0.027)$ \\
Marital $\times$ College & 0.001 & 0.003 & $0.070^{* *}$ & 0.005 \\
Nonwhite & $(0.016)$ & $(0.024)$ & $(0.025)$ & $(0.027)$ \\
& $-0.038^{* * *}$ & $-0.042^{* * *}$ & $-0.041^{* * *}$ & $-0.041^{* * *}$ \\
Children in HH & $(0.010)$ & $(0.010)$ & $(0.010)$ & $(0.010)$ \\
Wealth-to-income ratio & $-0.009^{* * *}$ & $-0.007^{* *}$ & $-0.010^{* * *}$ & $-0.010^{* * *}$ \\
& $(0.002)$ & $(0.002)$ & $(0.003)$ & $(0.003)$ \\
Age & $0.004^{* * *}$ & $0.004^{* * *}$ & $0.004^{* * *}$ & $0.004^{* * *}$ \\
& $(0.000)$ & $(0.000)$ & $(0.000)$ & $(0.000)$ \\
Age sq./100 & $0.006^{* * *}$ & $0.006^{* *}$ & $0.007^{* * *}$ & $0.008^{* * *}$ \\
High School & $(0.002)$ & $(0.002)$ & $(0.002)$ & $(0.002)$ \\
& $-0.007^{* * *}$ & $-0.006^{* *}$ & $-0.008^{* * *}$ & $-0.009^{* * *}$ \\
College & $(0.002)$ & $(0.002)$ & $(0.002)$ & $(0.002)$ \\
Year Dummies & 0.017 & 0.012 & 0.011 & 0.018 \\
N & $(0.010)$ & $(0.010)$ & $(0.010)$ & $(0.010)$ \\
& $0.125^{* * *}$ & $0.120^{* * *}$ & $0.119^{* * *}$ & $0.125^{* * *}$ \\
& $(0.011)$ & $(0.011)$ & $(0.011)$ & $(0.011)$ \\
& yes & yes & yes & yes \\
& 17392 & 17187 & 16984 & 16753 \\
\hline
\end{tabular}

This table reports marginal effects from separate random effects tobit regressions of the stock share on marital status, children living at home, and other household characteristics. Separate regressions were estimated for men and women and for two marital status categories: "Divorced" includes respondents who are either divorced or married, and "Never-married" includes those who are either never-married or married. The interpretation of the indicator variable "Marital x Edu" depends on the subsample, such that "Marital" corresponds to "Divorced" or "Never-married," depending on the column of interest. "Children in HH" is the number of children living at home. "Wealth-income ratio" is the average ratio of net wealth to income. Data taken from the 1999-2005 wealth supplements in the PSID and restricted to respondents aged 20 to 70 The stock share is the net value of stocks (directly-held, mutual funds, and investment trusts) divided by net financial wealth. Asterisks denote the following levels of statistical significance: ${ }^{*} p<0.05,{ }^{* *} p<0.01$, ${ }^{* * *} p<0.001$. See text for details. 

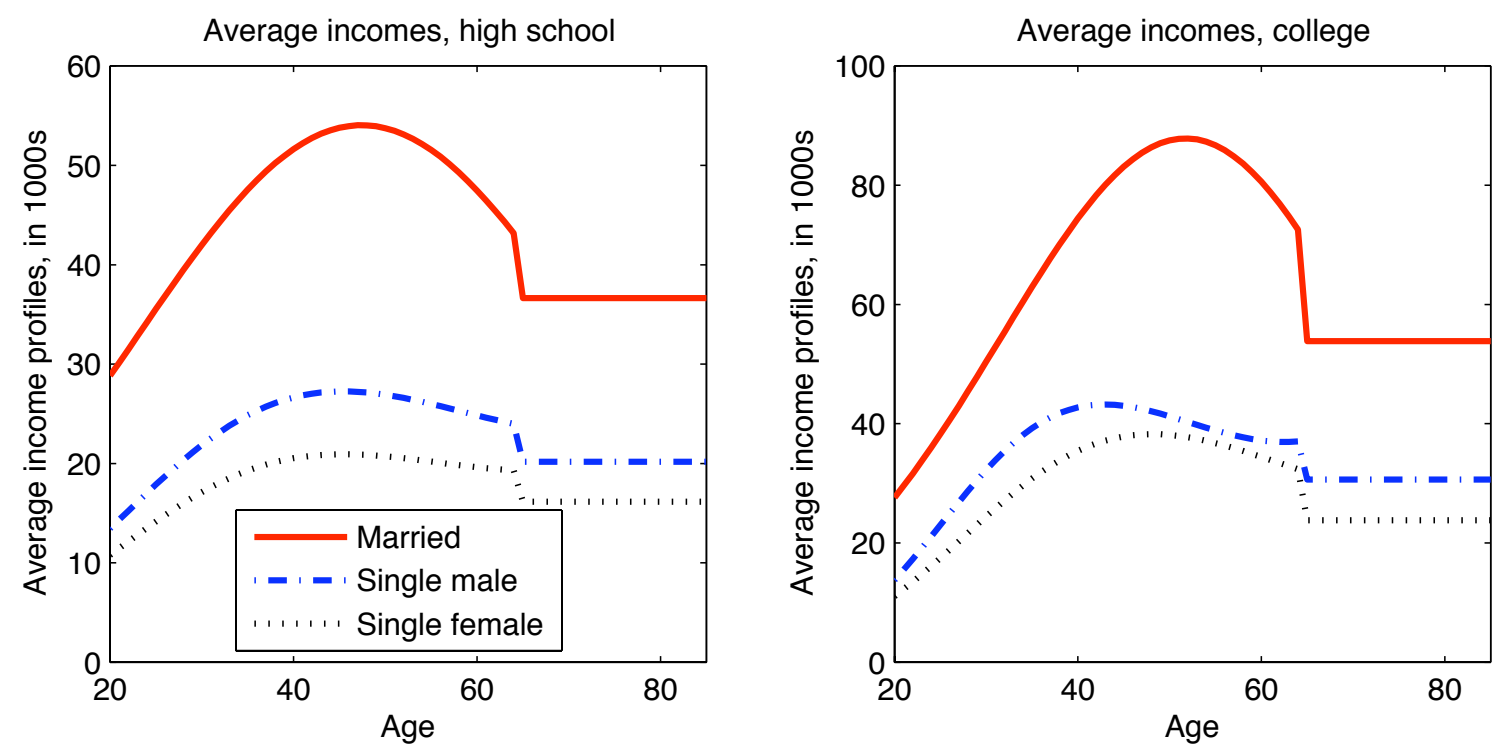

Figure 1

Estimated income profiles: This figure displays the average income profiles (in thousands of 2006 dollars) by marital status and education. The profiles are constructed using the coefficient estimates and fitted age polynomials reported in Table 1, with the number of children living at home set to zero. The data for working-age incomes come from the 1980-2003 waves of the PSID, and the replacement rate of retirement income is calculated using the 1992-2006 waves of the HRS. 

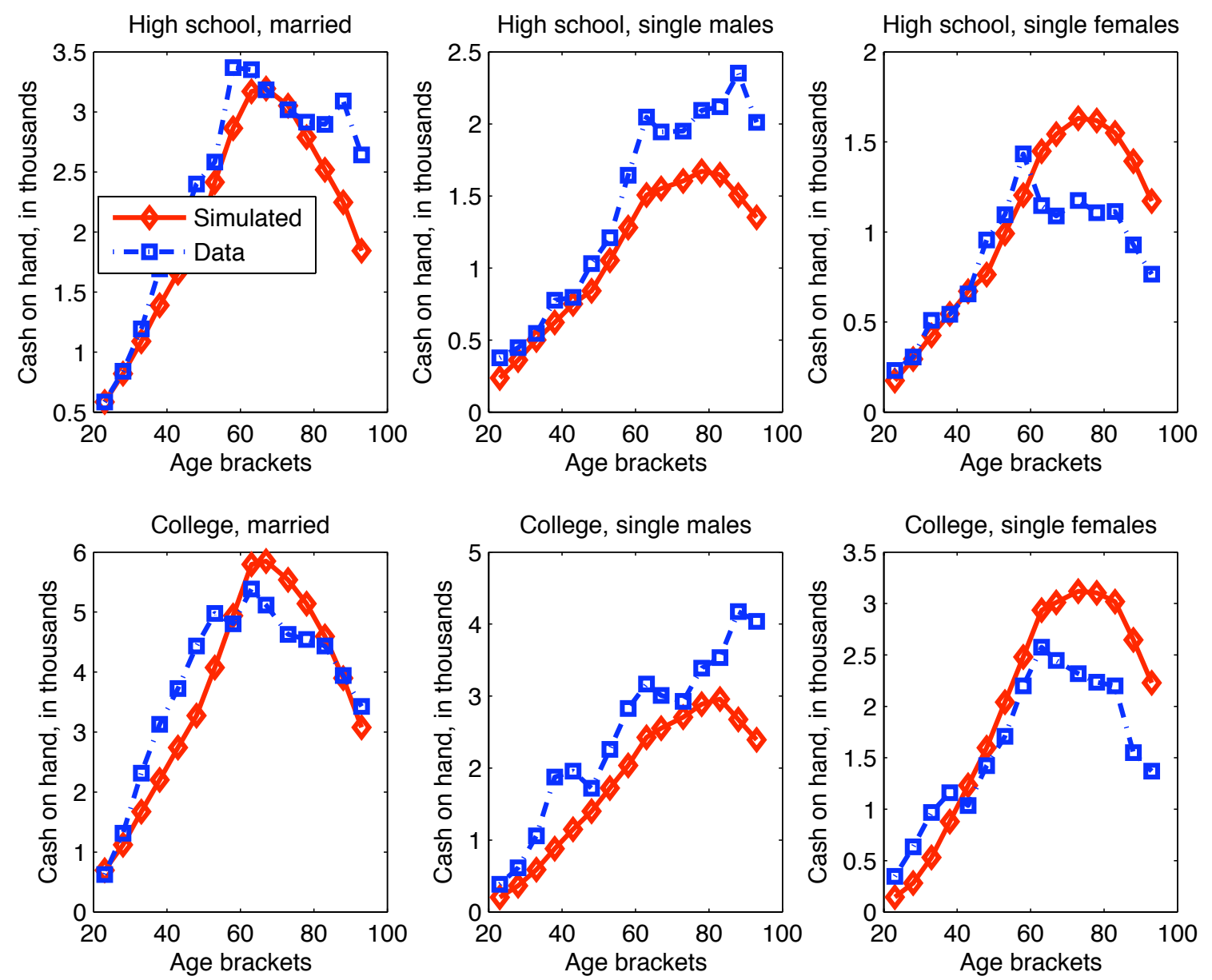

Figure 2

Comparison of simulated and empirical wealth levels: This figure compares the median levels of cash on hand from the HRS and PSID with the median profiles from the model simulations for married couples, single males, and single females (in 2006 dollars). The median wealth levels for ages 20-65 were calculated using the 1999-2005 wealth supplements in the PSID. The medians for ages 65-95 were calculated using the 1992-2006 waves of the HRS. The samples are restricted to observations with cash on hand between $\$ 0$ and $\$ 3,000,000$ and incomes greater than $\$ 3,000$. The simulated profiles were generated with a coefficient of relative risk aversion $\rho=6$ and the pair of the discount factor $\beta$ and the bequest parameter $b$ that minimizes the sum of squared deviations between the simulated and empirical median cash-on-hand to income ratios for 5 -year age brackets between 20 and 95. For high school graduates, $\beta=0.9215$ and $b=3.25$, and for college graduates, $\beta=0.9050$ and $b=4.00$. See text for details. 

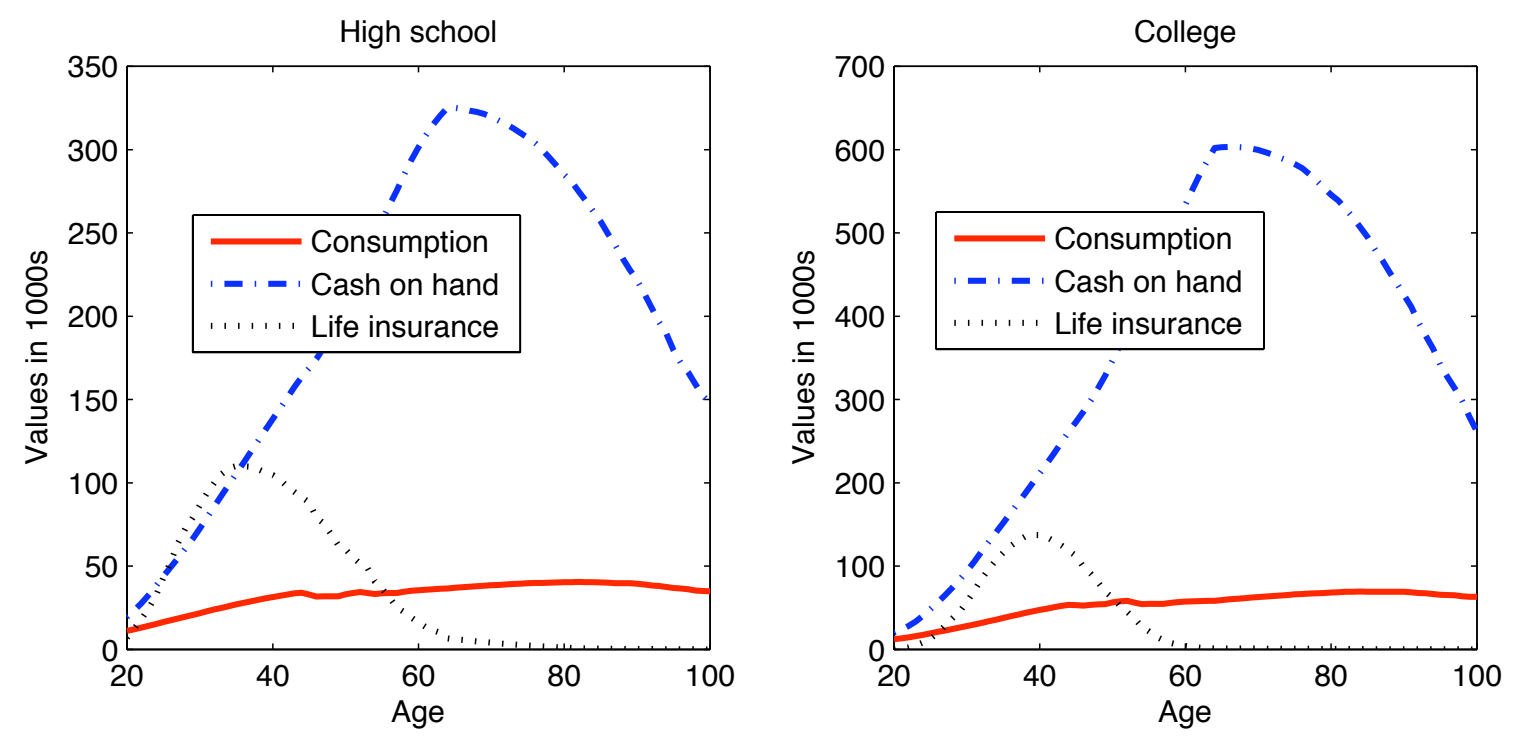

Figure 3

Simulated consumption, cash on hand, and life insurance: This figure shows the average simulated levels of household consumption, $C_{t}$, cash on hand, $X_{t}$, and the face value of life insurance, $Q_{t}$, for all married and single male high school graduates (left panel) and college graduates (right panel). Averages are taken over 50,000 independent simulations of returns, income, children, marital status, and mortality for the baseline specification of the model. The baseline model is solved for a coefficient of relative risk aversion $\rho=6$, a correlation between stocks and permanent income $\operatorname{corr}_{r, y}=0.15$, and the pair of the discount factor $\beta$ and the bequest parameter $b$ that minimizes the sum of squared deviations between the simulated and empirical median cash-on-hand to income ratios for 5-year age brackets between 20 and 95 . For high school graduates, $\beta=0.9215$ and $b=3.25$, and for college graduates, $\beta=0.9050$ and $b=4.00$. 

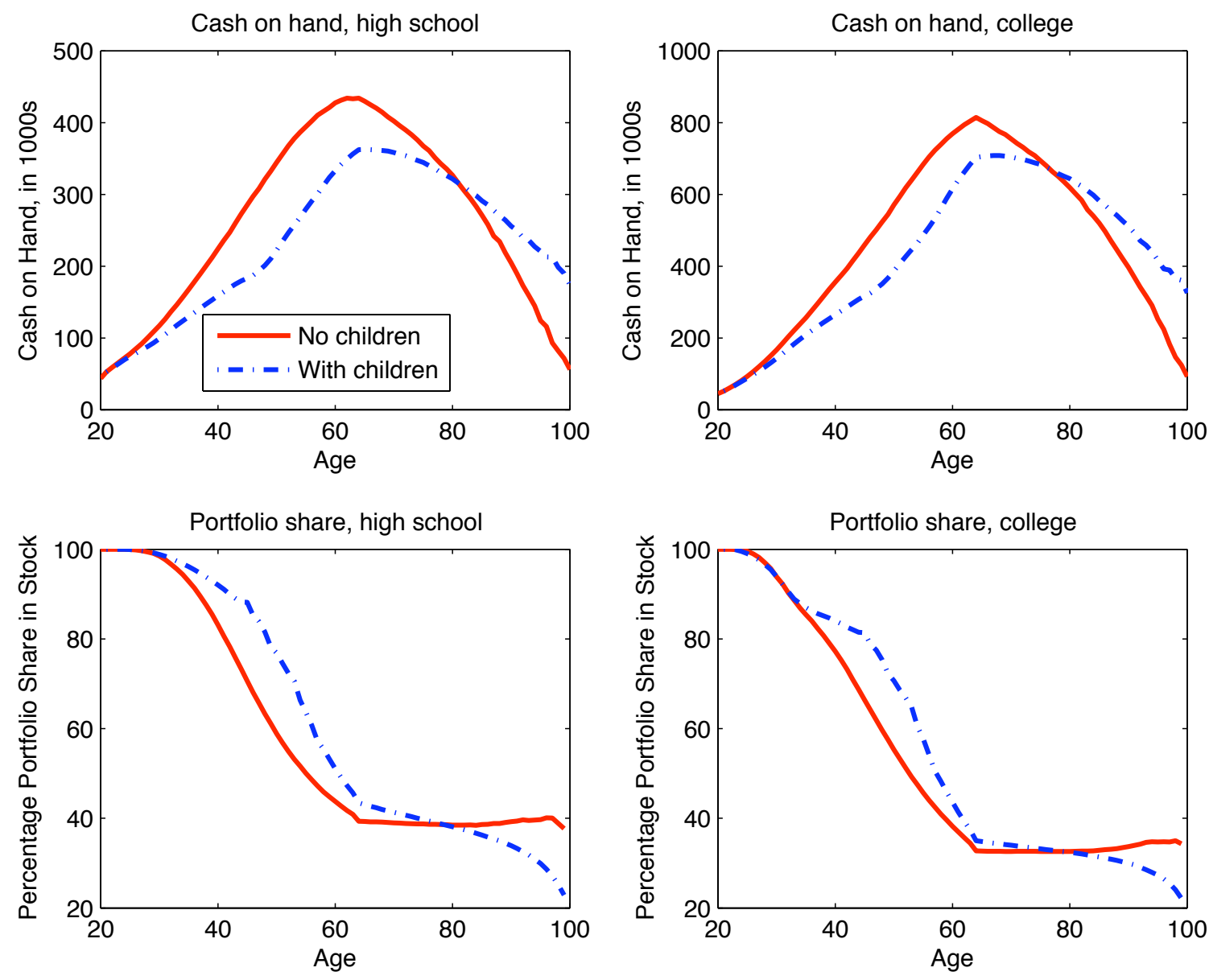

\section{Figure 4}

Simulated cash on hand and portfolio shares for married families with and without children: The top two panels of the figure show the average simulated levels of cash on hand, $X_{t}$, for married high school (left panel) and college (right panel) graduates with children (solid red line) and without children (dashed blue line). The bottom two panels show the simulated portfolio share, $\varsigma_{t}$. Averages are taken over 50,000 independent simulations of returns, income, children, marital status, and mortality for the baseline specification of the model. The baseline model is solved for a coefficient of relative risk aversion $\rho=6$, a correlation between stocks and permanent income $\operatorname{corr}_{r, y}=0.15$, and the pair of the discount factor $\beta$ and the bequest parameter $b$ that minimizes the sum of squared deviations between the simulated and empirical median cash-on-hand to income ratios for 5 -year age brackets between 20 and 95 . For high school graduates, $\beta=0.9215$ and $b=3.25$, and for college graduates, $\beta=0.9050$ and $b=4.00$. 

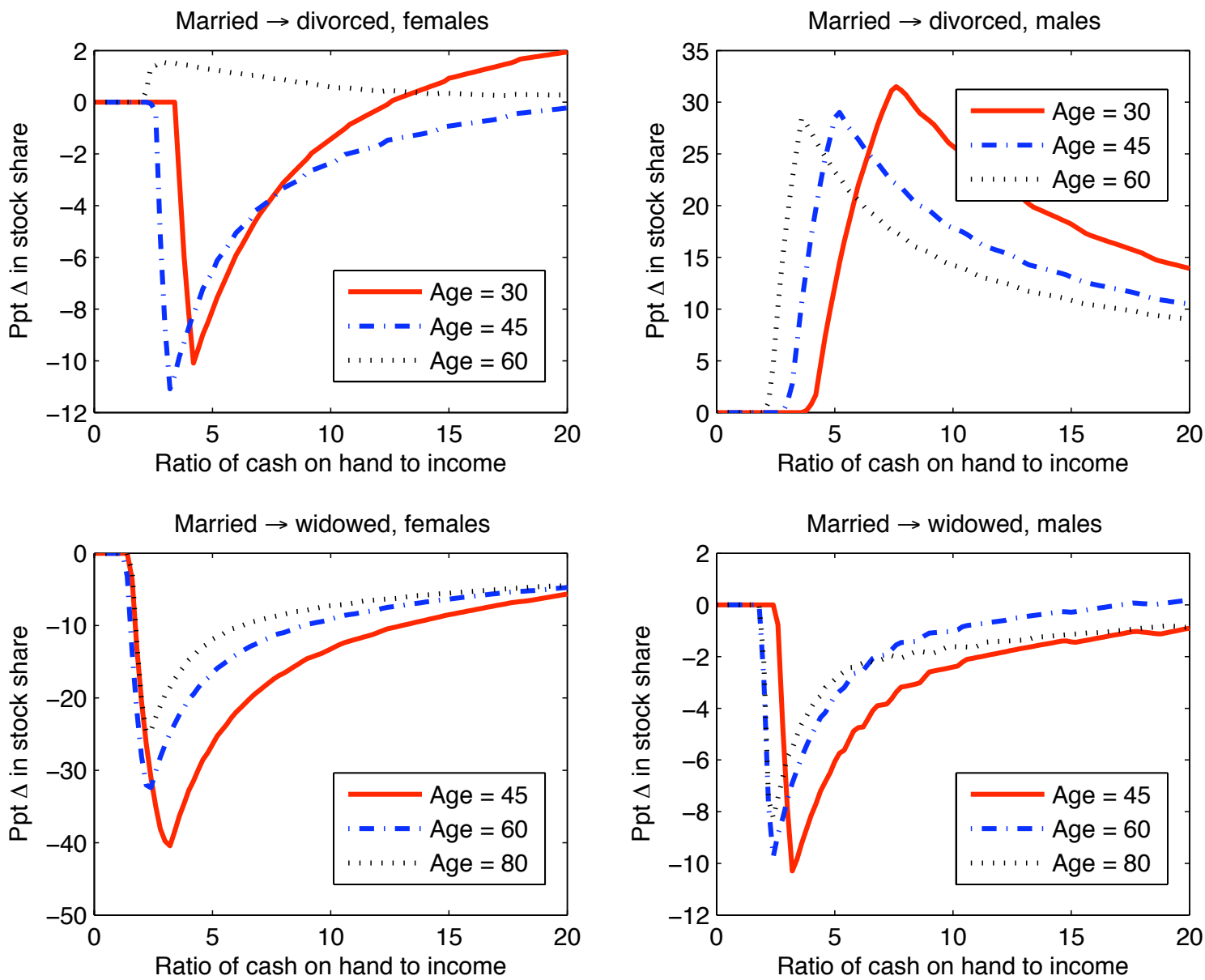

Figure 5

Percentage point change in portfolio shares due to divorce or widowhood (high school): This figure shows the percentage point change in the portfolio share in risky assets due to a transition to divorce or widowhood for male and female high school graduates. The left panels show the changes for men, and the right panels show the changes for women. The percentage point change is calculated using the decision rules for optimal portfolio choice, holding the realizations of permanent income, transitory income, and asset returns to their expected values. See text for details. 

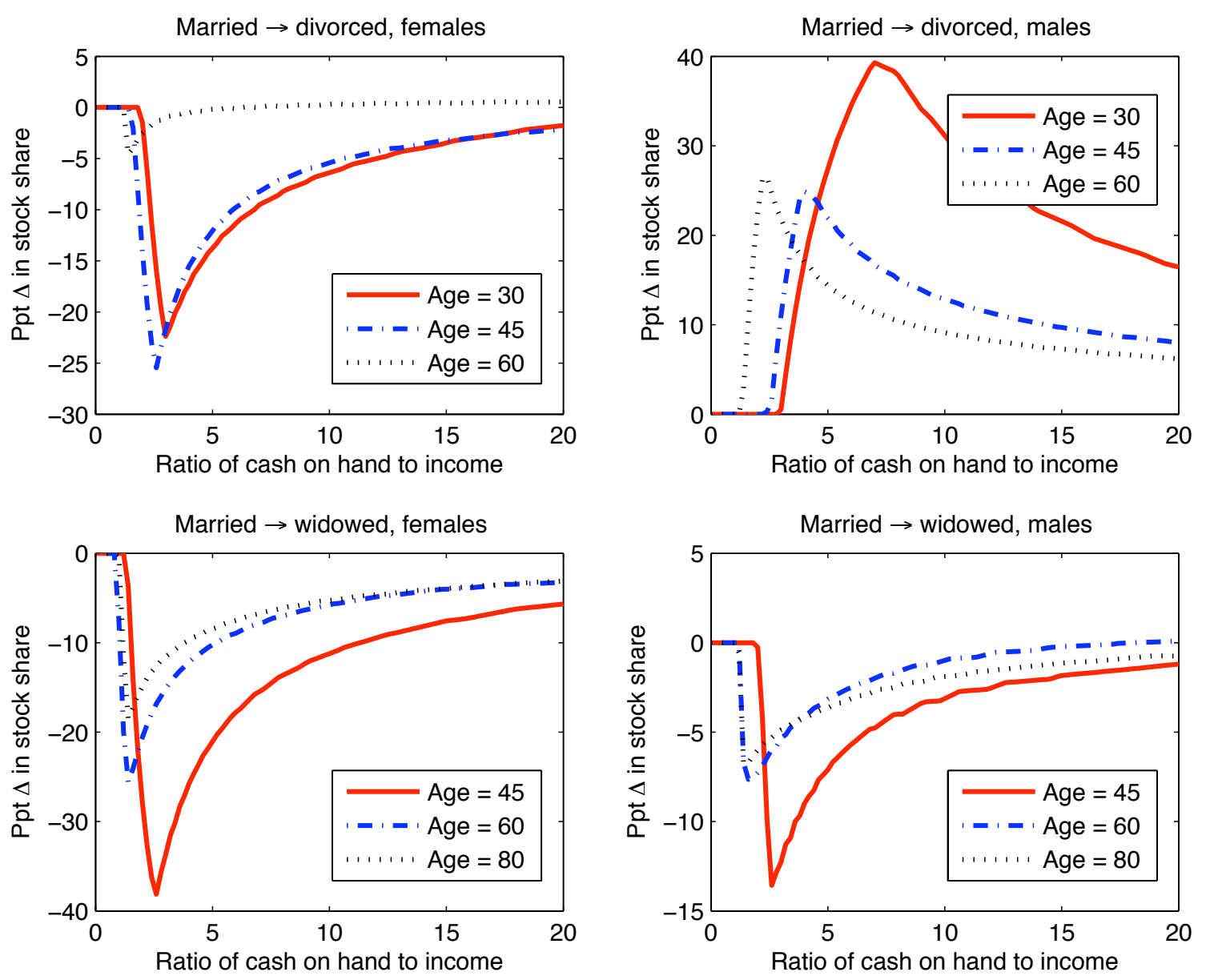

Figure 6

Percentage point change in portfolio shares due to divorce or widowhood (college): This figure shows the percentage point change in the portfolio share in risky assets due to a transition to divorce or widowhood for male and female college graduates. The left panels show the changes for men, and the right panels show the changes for women. The percentage point change is calculated using the decision rules for optimal portfolio choice, holding the realizations of permanent income, transitory income, and asset returns to their expected values. See text for details. 

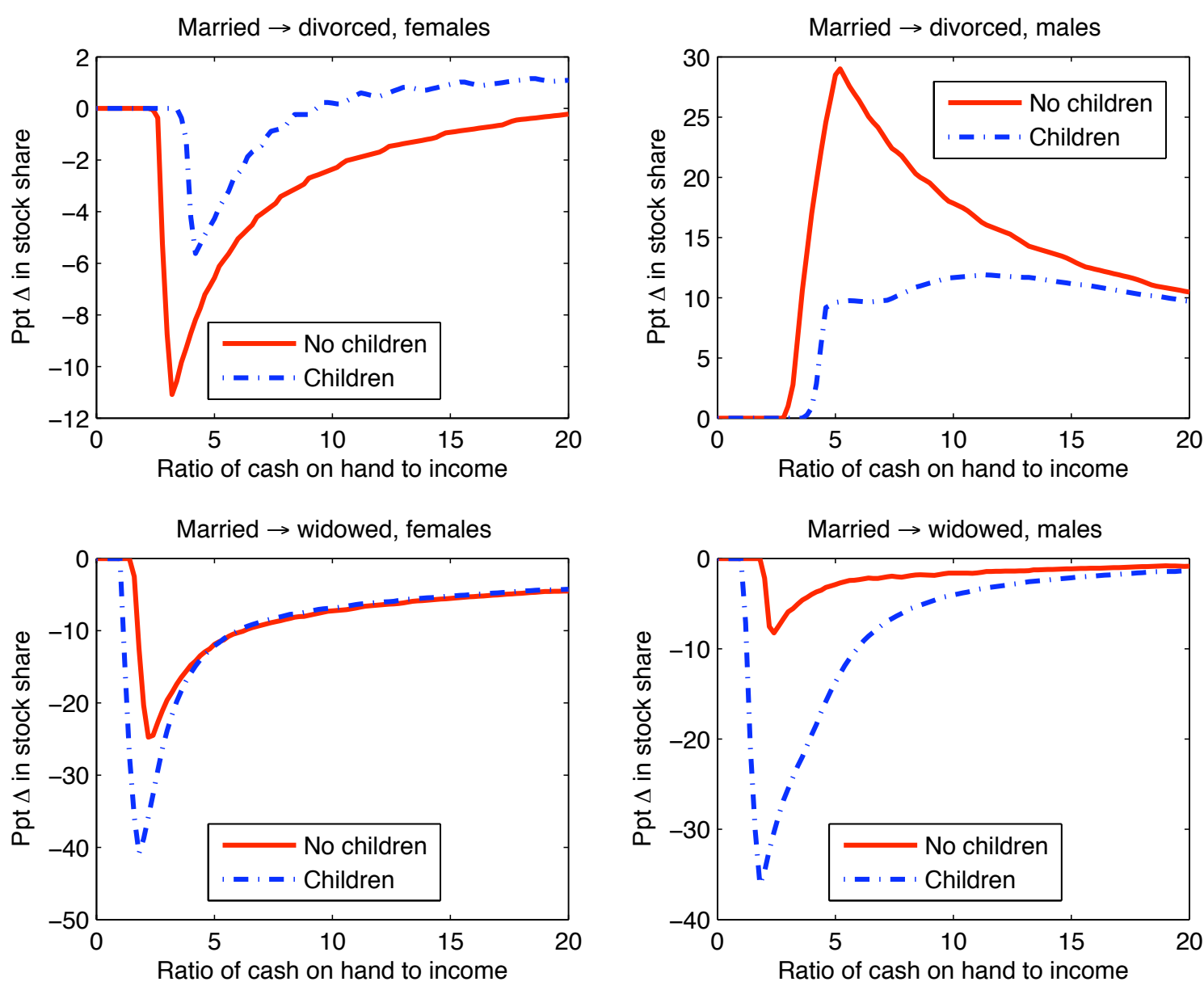

Figure 7

Effect of children on the change in portfolio shares due to divorce or widowhood (high school): This figure shows the percentage point change in the portfolio share in risky assets due to a transition to divorce or widowhood for male and female high school graduates. In the plots, divorced individuals are 45 years old and widowed individuals are 80 years old. The solid red line shows the change for households without children, and the dashed blue line shows the change for a household with two children born in the "early" period and one child born in the "late" period. The left panels show the changes for men, and the right panels show the changes for women. The percentage point change is calculated using the decision rules for optimal portfolio choice, holding the realizations of permanent income, transitory income, and asset returns to their expected values. See text for details. 

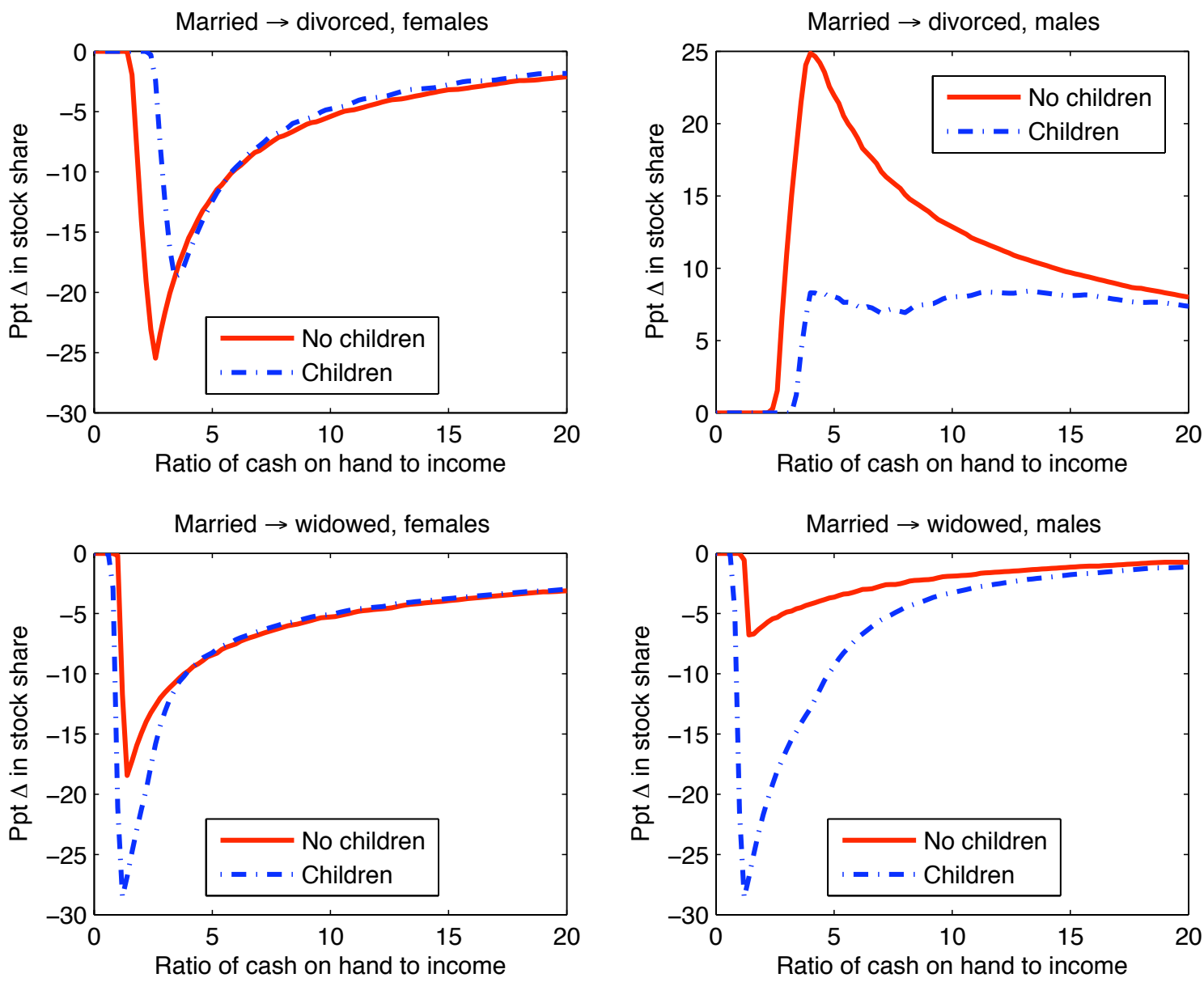

Figure 8

Effect of children on the change in portfolio shares due to divorce or widowhood (college): The figure shows the percentage point change in the portfolio share in risky assets due to a transition to divorce or widowhood for male and female college graduates. In the plots, divorced individuals are 45 years old and widowed individuals are 80 years old. The solid red line shows the change for households without children, and the dashed blue line shows the change for a household with two children born in the "early" period and one child born in the "late" period. The left panels show the changes for men, and the right panels show the changes for women. The percentage point change is calculated using the decision rules for optimal portfolio choice, holding the realizations of permanent income, transitory income, and asset returns to their expected values. See text for details. 